\begin{tabular}{|c|l|}
\hline Title & Monophyletic Polyneoptera recovered by wing base structure \\
\hline Author(s) & Yoshizawa, Kazunori \\
\hline Citation & $\begin{array}{l}\text { Systematic Entomology, 36/3), 377-394 } \\
\text { https:/doi.org/10.1111j.1365-3113.2011.00572.x }\end{array}$ \\
\hline Issue Date & 2011-07 \\
\hline Doc URL & http://hdl.handle.net/2115/49480 \\
\hline Rights & The definitive version is available at http://onlinelibrary.wiley.com/ \\
\hline Type & article (author version) \\
\hline File Information & SE36-3_377-394.pdf \\
\hline
\end{tabular}

Instructions for use 
Running title: Phylogeny of Polyneoptera

\title{
Monophyletic Polyneoptera recovered by the wing base structure
}

\author{
KAZUNORI YOSHIZAWA
}

Systematic Entomology, Graduate School of Agriculture, Hokkaido University, Sapporo, Japan

Correspondence: Kazunori Yoshizawa, Systematic Entomology, Graduate School of Agriculture, Hokkaido University, Sapporo 060-8589, Japan. E-mail.

psocid@res.agr.hokudai.ac.jp

\begin{abstract}
Phylogenetic relationships among the winged orders of Polyneoptera (Blattodea, Dermaptera, Embiodea or Embioptera, Isoptera, Mantodea, Orthoptera, Phasmatodea, Plecoptera, Zoraptera) were estimated based on morphological data selected from the hindwing base structure. Cladistic analyses were carried out using the hindwing base data alone and in combination with other, more general, morphological data. Both data sets resulted in similar trees and recovered monophyly of Polyneoptera. Deepest phylogenetic relationships among the polyneopteran orders were not confidently estimated, but monophyly of Mystroptera (= Embiodea + Zoraptera), Orthopterida (= Orthoptera + Phasmatodea) and Dictyoptera (= Blattodea + Mantodea + Isoptera) was supported consistently. In contrast, placements of Plecoptera and Dermaptera were unstable, although independent analysis of the wing base data supported their sister group relationship with two non-homoplasious synapomorphies (unique conditions in the ventral basisubcostale and in the articulation between the antemedian notal wing process and first axillary sclerite). Results from the combined wing base plus general morphology data were consistent even if the wingless orders Grylloblattodea and Mantophasmatodea were included in the analysis. Generally, trees obtained from the present analyses were concordant with the results from other morphological and molecular analyses, but Isoptera were placed inappropriately to be the sister of Blattodea

+ Mantodea by inclusion of the wing base data, probably due to morphological regressions of the order.
\end{abstract}

\section{Introduction}

Among the deep insect phylogeny, relationships among the polyneopteran orders are the least resolved problem (Kristensen, 1991). The Polyneoptera are composed of the orders Blattodea, Dermaptera, Embiodea (= Embioptera or Embiidina), Grylloblattodea, Isoptera, Mantodea, Mantophasmatodea, Orthoptera, Phasmatodea, Plecoptera, and Zoraptera (Grimaldi \& Engel, 2005). Monophyly of Dictyoptera (= Blattaria + Isoptera + Mantodea) and Xenonomia (= Grylloblattodea + Mantophasmatodea) is now widely accepted (Grimaldi \& Engel, 2005; Gullan \& Cranston, 2010). However, phylogenetic relationships among other orders are almost completely unresolved and very unstable. For example, Zoraptera were once considered to be a paraneopteran order (= hemipteroid assemblage) (Hennig, 1966, 1981; Beutel \& Gorb, 2006), and their status as a polyneopteran order was only recently confirmed molecularly (Yoshizawa 
\& Johnson, 2005; Ishiwata et al., 2011) and morphologically (Grimaldi \& Engel, 2005; Yoshizawa, 2007). Some supraordinal taxa have been proposed [e.g., Plecopterida (= Plecoptera + Embiodea + Zoraptera) and Orthopterida (= Orthoptera + Phasmatodea) (Grimaldi $\&$ Engel, 2005)] but they are not widely accepted. Furthermore, the validity of Polyneoptera is also a long debated problem (Boudreaux, 1979; Hennig, 1981; Kristensen, 1991; KukalovaPeck, 1991; Jamieson et al., 1999; Haas \& Kukalova-Peck, 2001; Grimaldi \& Engel, 2005; Gullan \& Cranston, 2010), and morphological studies have not provided consistent evidence for monophyly of Polyneoptera. Therefore, an informal name, lower Neoptera, has also been proposed for this assemblage (Kristensen, 1991).

Molecular-based approaches have also been applied to the Polyneoptera problem. In estimating deep insect phylogeny, very slowly evolving $18 \mathrm{~S}$ rDNA has been used most widely (Kjer, 2004; Yoshizawa \& Johnson, 2005; Misof et al., 2007). However, this gene marker is problematic especially for the phylogenetic analyses of polyneopterans because of a combination of unusual evolutionary trends of this gene as observed in some groups (especially the $18 \mathrm{~S}$ of Zoraptera shows extreme acceleration of substitution rate and modifications of secondary structure: Kjer, 2004; Yoshizawa \& Johnson, 2005). Wheeler et al. (2001) and Terry \& Whiting (2005) analyzed polyneopteran phylogeny using multiple nuclear gene markers (18S, 28S and/or Histone 3) plus morphology. Superficially, their analyses provided well resolved results, but problems have been identified in their analytical method (Kjer, 2004; Simmons, 2004; Morgan \& Kelchner, 2010; Yoshizawa, 2010) and in inclusion some dubious sequences (Yoshizawa, 2010, 2011). Kjer et al. (2006) analyzed the insect phylogeny with various combinations of multiple nuclear and mitochondrial genes $(18 \mathrm{~S}, 28 \mathrm{~S}$, Histone 3, EF-1 $\alpha$, COI, COII, 12S, 16S) and morphology, and excluding the problematic taxon Zoraptera. However, they still failed to obtain a well supported tree concerning the deep polyneopteran branches (Whitfield \& Kjer, 2008). The latest analyses of three nuclear protein-coding genes (DNA polymerase delta and two subunits of RNA polymerase II) provided a reasonable support for monophyly of the Polyneoptera, but intraordinal relationships remain poorly resolved (Ishiwata et al., 2011). Therefore, no molecular-based approaches yet have provided a robust hypothesis for the phylogeny of Polyneoptera (Kjer et al., 2006; Whitfield \& Kjer, 2008).

The insect wing base structure has attracted attention as a source of deep phylogenetic information (Yoshizawa \& Saigusa, 2001; Hörnschemeyer, 2002; Hörnschemeyer \& Willkommen, 2007; Yoshizawa, 2007). This character system, which consists of tightly associated sclerites which control very sophisticated movement of insect wings (flapping, rotating, and folding: Brodsky, 1994), evolves very slowly (Hörnschemeyer, 2002). The presence of many sclerites, articulations, and folding lines in the wing base area provides robust evidence for topological correspondence (Rieppel \& Kearney, 2002) allowing identification of homology of the sclerites. Notably, some reliable landmarks guarantee homologization of the wing base sclerites even between distantly related orders (Yoshizawa, 2007; Yoshizawa \& Ninomiya, 2007; Ninomiya \& Yoshizawa, 2008). These characteristics of the wing base structure allow us to select many qualitative data which are expected to contain useful information also for uncovering the deep polyneopteran phylogeny.

In this study, I examine morphology of the hindwing base structure throughout the polyneopteran orders. Based on this, potentially informative characters for polyneopteran 
phylogenetic estimation are selected from the character system, and maximum parsimony analyses are performed based on two data sets: the independent wing base data and the wing base plus general morphological data combined. The phylogeny of the polyneopteran orders is discussed based on the resulting trees.

\section{Materials and Methods}

The hindwing base structure alone was subjected to the present analyses following Yoshizawa (2007). Observations were made by Olympus SZX16 stereoscopic microscope and Zeiss Axiphoto compound light microscope. The folding lines were identified based on the $\mathrm{KOH}$ soaked but undissected specimens. The right wing was used for observation of the dorsal structure and, to facilitate observation, the pleurite and ventral layer of the wing were removed from the notum and dorsal wing layer. The left wing was used for observation of the ventral structures and, to facilitate observation, the dorsal structures (notum, dorsal axillary sclerites and dorsal layer of the wing) were removed from the pleurite and ventral wing layer. Previous interpretations of the homology of the hindwing base structure proposed by myself also were revised critically (Appendix 3: Yoshizawa \& Saigusa, 2001; Yoshizawa, 2007; Yoshizawa \& Ninomiya, 2007; Ninomiya \& Yoshizawa, 2009).

Taxa examined are listed in Appendix 1. Each order was treated as a terminal taxon but, for Orthoptera, two suborders, Ensifera and Caelifera, were treated as separate terminal taxa (Beutel \& Gorb, 2001, 2006). Outgroups were selected from two palaeopteran orders, Ephemeroptera and Odonata. Trees were rooted with Odonata based on recent results from molecular-based phylogenetic analyses (Kjer, 2004; Yoshizawa \& Johnson, 2005; Simon et al., 2009). Three non-polyneopteran orders, Psocodea (retaining the most plesiomorphic wing base conditions in Paraneoptera: Yoshizawa \& Saigusa, 2001), Megaloptera and Mecoptera (two holometabolans thought to be relict orders: Grimaldi \& Engel, 2005), were also examined and employed for the analyses to test monophyly of Polyneoptera.

Cladistic analyses were performed using two data sets: a data set composed of the wing base characters only (referred to hereafter as the wing base data); and a data set combined the wing base characters with other general characters presented in Beutel \& Gorb (2006) (referred to hereafter as the total data). In the characters scored by Beutel \& Gorb, characters 45 and 47 (Beutel \& Gorb, 2006: BG06), which correspond to 87 and 89 in the present total data matrix (see Supporting Information), already have been scored in the wing base data. Therefore, these two characters were excluded from the analysis of the total data. For character 49 of BG06, state 2 was given for Embiodea (Beutel \& Gorb, 2006: appendix 2), but this was changed to 0 according to Beutel \& Gorb (2001: BG01). I prepared two taxon sets for the total data: including the winged orders only (total data) and two wingless orders (Grylloblattodea and Mantophasmatodea) incorporated [total data (+wingless)]. All data sets were analyzed using PAUP* 4.0b10 (Swofford, 2002), with branch-and-bound search option. Bremer support value was calculated using TreeRot 3 (Sorenson \& Franzosa, 2007). The character state changes and the consistency and retention indices (ci and ri) were calculated using MacClade 4 (Maddison \& Maddison, 2001).

Terminology of the wing base sclerites follows Brodsky (1994) and Matsuda (1970). Terminology of the folding lines follows Wootton (1979). The following abbreviations are used in the text and figure plates: anterior, antemedian, median, posterior notal wing processes 
= ANWP, AmNWP, MNWP, PNWP; first, second, third axillary sclerites = 1, 2, 3Ax; proximal, distal median plates $=$ PMP, DMP; tegula $=\mathrm{Tg}$; humeral plate $=\mathrm{HP}$; basisubcostale $=\mathrm{BSc}$; basiradiale $=\mathrm{BR}$; pleural wing process $=\mathrm{PWP}$; basalare $=\mathrm{Ba}$. In the text, the numbers followed by a bracket indicate the character number, and the numbers in the brackets indicate state of the character (Appendix 2).

\section{Comparative Morphology of Polyneopteran Hindwing Base (Figs 1-13)}

[Note: For detailed structures of the wing bases in Odonata and Ephemeroptera, see Yoshizawa \& Ninomiya (2007) and Ninomiya \& Yoshizawa (2009). These papers treat the forewing base structure only, but the hindwing base of these insect groups are almost analogous with the forewing base, although sclerotization of the hindwing base of Ephemeroptera is much weaker than the forewing base (present observation). In addition, the above papers treat the dorsal structures only. However, the basalare and humeral plates, which are almost always placed in the ventral region of the neopteran wing base, are both placed in the dorsal region and/or on the anterior margin of the wing base in Odonata and Ephemeroptera and thus are also illustrated and described in the papers.]

The notum has three principal wing processes, anterior (ANWP), median (MNWP) and posterior notal wing processes (PNWP). The anterolateral scutal suture has its lateral end near the tip of ANWP. The apex of ANWP almost always is located beneath the anteroproximal margin of the neck of $1 \mathrm{Ax}$, forming the anterior-most articulation between the notum and axillary region (= the basal hinge). In Phasmatodea and Caelifera of Orthoptera, however, ANWP articulates with $2 \mathrm{Ax}$ or BR because of desclerotization of the neck of $1 \mathrm{Ax}$ (Figs 7, 8). Usually, ANWP and 1Ax articulate at a point or along very short margins (e.g., Fig. 1) but, in Blattodea, Mantodea and some isopterans, these articulate along long margins (Figs 3-5). In most polyneopterans (except for Zoraptera: Fig. 10) and holometabolans, the antemedian notal wing process (AmNWP) clearly is developed at the posterodistal corner of ANWP. AmNWP articulates with the anteroproximal corner of the body of 1Ax in many orders [Plecoptera, Dermaptera, Blattodea, some mantodeans, some orthopterans, and Embiodea (e.g., Fig. 3)], but such tight articulation is not confirmed in others (e.g., Fig. 8). When the AmNWP-1Ax articulation is observed, their relationships are variable: forming a side-by-side articulation in Plecoptera, Dermaptera, Blattodea, Mantodea, and Embiodea (e.g., Fig. 1) whereas AmNWP is placed over 1Ax in some orthopterans (Fig. 7). AmNWP of Caelifera looks quite different from that of other insects in its much weaker sclerotization and more distant placement from ANWP (Fig. 7). Therefore, alternative interpretations could be possible regarding the homology of caeliferan AmNWP. However, AmNWP of Caelifera is considered here to be homologous with that of other insects because it is located just posterior to ANWP and there is no other structure that possibly could correspond to AmNWP. In Plecoptera and Dermaptera, 1Ax has a flap-like expansion at the articular point with AmNWP. MNWP also articulates with the proximal margin of the body of $1 \mathrm{Ax}$ along the basal hinge. 1Ax and MNWP form a sideby-side articulation (e.g., Fig. 1), or MNWP is placed over 1Ax (e.g., Fig. 3). In palaeopteran, paraneopteran, and holometabolan orders, MNWP articulates with $1 \mathrm{Ax}$ at a point or along a short margin (Figs 11-13) but, in Polyneoptera, the posteroproximal tail of 1Ax is elongated, and MNWP articulates with 1Ax along a long margin (Figs 1-10). However, in Mantodea, the elongated tail of $1 \mathrm{Ax}$ articulates with MNWP only at a point with its posterior tip (Fig. 4). 
PNWP extends from the posterolateral corner of the notum and articulates with the proximal tip of $3 \mathrm{Ax}$, which forms the posterior-end of the basal hinge (e.g., Fig. 1). PNWP is separated from the notum in many orders (some plecopterans, Orthoptera, Phasmatodea, some embiodeans, Zoraptera, Mecoptera and Megaloptera: e.g., Fig. 1) but is fused to the notum in others (e.g., Fig. 3).

The axillary region consists of three axillary sclerites (first, second and third axillary sclerites), two median plates (proximal and distal median plates), and some basal sclerites of veins (humeral plate or basicostale, basisubcostale and basiradiale). 1Ax is a single sclerite, but generally three regions are recognized in it: i.e., head, neck and body (Hörnschemeyer, 2002). The head and neck regions usually are much narrower than the body (e.g., Fig. 1) but, in Embiodea and Zoraptera, these regions are extremely broadened, almost as wide as the body width (Figs 9, 10). In Phasmatodea and Caelifera of Orthoptera, the neck region of 1Ax becomes membranous (Figs 7,8) and, in the latter, the head also is completely desclerotized (Fig. 7). The body of $1 \mathrm{Ax}$ is a roughly triangular sclerite which articulates proximally with MNWP (and sometimes with AmNWP anteroproximally) along the basal hinge. Usually, 1Ax and PNWP are separated widely and the basal hinge line runs between them (e.g., Fig. 1) but, in Embiodea and Zoraptera, the proximal tail of 1Ax is elongated and fused to PNWP (Figs 9, 10). In Zoraptera and some embiodeans, the basal hinge runs between the notum and the separated PNWP (Fig. 10: see also Yoshizawa, 2007) but, in embiodeans with PNWP fused to the notum, the basal hinge does not form a clear line posteriorly (Fig. 9). Distally, the body of $1 \mathrm{Ax}$ articulates with 2Ax along a convex line (e.g., Fig. 1). 1Ax and 2Ax articulate at two points: anteriorly, the anteroproximal corner of $2 \mathrm{Ax}$ is usually placed over the anterodistal corner of the body of $1 \mathrm{Ax}$; posteriorly, the posterodistal corner of the body of $1 \mathrm{Ax}$ is usually placed over the posterior tip of 2Ax (e.g., Fig. 13). In Dictyoptera (= Blattodea + Mantodea + Isoptera), however, the anterior articulation is absent (Figs 3-5). The head of 1Ax articulates the proximal tip of BSc along the convex axillary fold line (e.g., Fig. 1), but the 1Ax-BSc articulation is absent in the Caelifera (Fig. 7) because of desclerotization of the head and neck of 1Ax. The head and neck of 1Ax are closely related with BR distally. In Phasmatodea, the head of $1 \mathrm{Ax}$ is partly fused to BR (Fig. 8). Although interpretation of the separated sclerite in Phasmatodea is somewhat ambiguous, I homologized it to be the head of 1 Ax because of its tight relationship with BSc (Fig. 8).

2Ax is usually a triangular and flat sclerite located just distal to the body of $1 \mathrm{Ax}$ (e.g., Fig. 1). Anteriorly, 2Ax is closely associated with BR, and they are partly fused with each other (e.g., Fig. 1) except for Embiodea (Fig. 9) and some plecopterans (Yoshizawa, 2007: fig. 1A). In some Caelifera, the anteroproximal corner of $2 \mathrm{Ax}$ strongly extends anteriorly to which ANWP articulates, probably due to the desclerotization of the neck of 1Ax (Fig. 7). Distally, 2Ax forms a side-by-side articulation with PMP along the concave axillary fold line (e.g., Fig. 1). $2 \mathrm{Ax}$ and PMP are usually clearly divided (e.g., Fig. 1) but are partly fused by bending cuticle in Dictyoptera and some plecopterans (Figs 3-5). The posterior tip of 2Ax articulates with the anterior lobe of $3 \mathrm{Ax}$ along the concave axillary fold line (e.g., Fig. 1). Medially, 2Ax has a ligament toward the ventral sclerite of $2 \mathrm{Ax}$ (e.g., Fig. 1) but, in Embiodea and Zoraptera, the ligament is invaginated from the posterior tip of $2 \mathrm{Ax}$ (Figs 9, 10).

3 Ax consists of three-lobes (e.g., Fig. 1), called proximal, anterior and distal lobes. The proximal lobe articulates with PNWP along the basal hinge. The anterior lobe articulates with 
the posterior tip of 2Ax along the concave axillary folding line. The distal lobe articulates with the base of the anal veins along a convex line.

PMP is a roughly triangular sclerite located just distal to $2 \mathrm{Ax}$ (e.g., Fig. 1). The anterior tip of PMP articulates with BR along the convex axillary fold line. PMP is also associated with the anterior margins of the anterior and distal lobes of 3Ax. Reduction of PMP is relatively frequent, with its anterior region (Dermaptera, Megaloptera and Mecoptera: e.g., Fig. 2) or proximal region (Embiodea and Zoraptera: Figs 9, 10) broadly membranous. DMP is placed distal to PMP, and they form a side-by-side articulation along the distal axillary flexion line (e.g., Fig. 1). The anterior margin of DMP is delimited by the radial vein, and the median and cubital veins arise from the distal margin of DMP. DMP of Dermaptera is broadly desclerotized (Fig. 2).

HP (humeral plate) is the basal sclerite of the costal vein which usually occupies both the dorsal and ventral surfaces through the anterior margin of the proximal region of the wings (Figs 11-13). In contrast, in Polyneoptera except for some species of Blattodea, HP is completely membranous on the dorsal surface and its sclerotization is limited to the ventral surface (e.g., Fig. 1). The polyneopteran HP is usually triangular in shape and is associated with the basalare ventrally at a point (e.g., Fig. 1) or along a broad margin (Mantodea and some Blattodea: Fig. 4B). However, in Caelifera of Orthoptera and Psocodea + Holometabola, the HP-Ba articulation becomes loose (Figs 7, 11-13). HP is also closely associated (e.g., Fig. 1) or even fused (Figs 3,4) to the ventral BSc, but their association becomes very loose in Orthoptera and Phasmatodea (Figs 6-8).

BSc represents the proximal end of the subcostal vein and is strongly sclerotized on both dorsal and ventral surfaces (e.g., Fig. 1). The ventral BSc usually has a simple anterior margin (e.g., Fig. 3) but, in Plecoptera and Dermaptera, its anterior margin has a keel (Figs 1, 2). In Dermaptera, the ventral BSc is separated from the vein (Fig. 2).

$\mathrm{BR}$ is the basal sclerite of the radial vein and is strongly sclerotized on the dorsal surface (e.g., Fig. 1). It is related proximally to the neck and head of $1 \mathrm{Ax}$ and posteriorly to the anterior margin of 2Ax. In contrast, in Blattodea and Mantodea, close association between BR and 1Ax is not observed (Figs 3, 4). The convex axillary fold line runs through BR, and the region becomes bending cuticle. In Orthoptera, Phasmatodea and some embiodeans (Figs 6-9), BR is strongly constricted or, in Zoraptera and some embiodeans (Fig 10: Yoshizawa, 2007), the proximal region of BR is separated from the radial vein along the convex axillary folding line.

The pleurite is also associated with the wing base through the pleural wing process (e.g., Fig. 1). Usually, the ventral sclerite of 2Ax sits on the tip of PWP but, in Zoraptera, PWP is closely associated with the ventral BSc (Fig. 10B). In Neoptera, Ba is in the pleural region and is placed anterior to PWP (e.g., Fig. 1). Dorsally, Ba is tightly associated with the proximal tips of the ventral HP (e.g., Fig. 1) and/or the ventral BSc (Figs 11-13). The subalare is on the membranous region posterior to PWP, but the structure is not examined further in this study because it has no direct articulation to any wing base sclerite.

Although it is not directly related to the wing base sclerites, $\mathrm{Tg}$ (tegula) is observed usually on the anterior margin of the wing base proximal to HP (e.g., Fig. 1). Absence or reduction of $\mathrm{Tg}$ is very frequent especially in the hindwing but, in Embiodea and Zoraptera, $\mathrm{Tg}$ is very strongly sclerotized and well developed (Figs 9A, 10A). 


\section{Phylogenetic Analyses (Figs 14, 15)}

Based on the above morphological examination, I selected a total of 41 characters from the hindwing base structure. Most were binary, but seven characters were coded as 3 or 4 state (Appendix 2 and Supporting Information). All character states were treated as unorderd. Cladistic analysis of the wing base data yielded five equally parsimonious trees (tree length=69, $\mathrm{CI}=0.71, \mathrm{RI}=0.73$ ), and their strict consensus tree is shown in Fig. 14. Monophyly of Polyneoptera was supported by four apomorphies, with two characters receiving ci and ri=1 ( 7 [1] and 15 [1]). The Polyneoptera could be subdivided into four clades, Orthopterida (= Orthoptera + Phasmatodea), Mystroptera (= Embiodea + Zoraptera), Dictyoptera (= Blattodea + Mantodea + Isoptera) and Plecoptera + Dermaptera. Monophyly of Plecoptera + Dermaptera was supported by two non-homoplasious apomorphies. Monophyly of Mystroptera was strongly supported by six apomorphies, with five non-homoplasious ones (5 [1], 16 [1], 17 [1], 30 [1] and 34 [2]). Monophyly of Orthopterida was supported by three apomorphies, with one character receiving ci and $\mathrm{ri}=1$ (25 [1]). Phasmatodea were proposed as sister to Caelifera, and this relationship was supported by a non-homoplasious synapomorphy. Monophyly of Dictyoptera was supported by two non-homoplasious apomorphies. Monophyly of Psocodea + Holometabola was not supported. Almost all branches received Bremer support value $=1$, but Mystroptera, Neoptera, Mantodea + Blattodea and Polyneoptera received higher Bremer support values.

By combining the wing base data with the BG06 data, a single most parsimonious trees was yielded, with tree length $=193, \mathrm{CI}=0.69$, and RI $=0.65$ (Fig. 15). Monophyly of Polyneoptera was supported also by the total data set, but no unambiguous support for this clade was obtained from the BG06 data. Monophyly of Mystroptera, Dictyoptera and Orthopterida also were supported by the total data as well as the independent wing base data, with increased Bremer support values. In contrast, monophyly of Plecoptera + Dermaptera was not supported, and the latter order was placed to the sister to Dictyoptera by two highly homoplasious wing base characters. Plecoptera were placed to the sister to all polyneopterans except for Mystroptera. Monophyly of Orthoptera was supported, and Phasmatodea were placed as its sister group. Monophyly of Psocodea + Holometabola was supported, with support of three wing base characters (of them, 26 [1] and 39 [1] were identified to be nonhomoplasious). The deepest branches within Polyneoptera also were clearly resolved, yet all received Bremer support value merely of 1, and none received support from the wing base data (Fig. 15).

Analysis of the total data (+wingless) yielded two equally parsimonious trees, with $\mathrm{L}=$ $199, \mathrm{CI}=0.68$, and $\mathrm{RI}=0.64$. Trees obtained from the total data (+wingless) were completely concordant with the tree obtained from the total data, with Grylloblattodea + Mantophasmatodea placed to be the sister to either Dermaptera or Orthopterida (Fig. 15, arrows). Monophyly of Polyneoptera was not collapsed by inclusion of the wingless taxa, but its Bremer support value decreased from 2 to 1 (Fig. 15).

\section{Discussion}

The characters selected from the wing base (41 characters) consist of over one-fourth of the combined wing base + BG06 data (159 characters). Of them, 10 are parsimony uninformative 
but, because I here treated orders or suborders as terminal taxa (Bininda-Emonds et al., 1998; Beutel \& Gorb, 2001, 2006), such uninformative characters also are valuable in defining monophyly of each terminal taxa. The retention index shows that the wing base structure contains more congruent phylogenetic signal $(\mathrm{RI}=0.73$ by independent analysis of the wing base data: Fig. 14) in compare to other morphological characters (RI $=0.63$ by independent analysis of the BG06 data: trees not shown). These suggest that the wing base structure has high potential to assist in estimating the higher level phylogenetic relationships among the winged insects, as suggested previously (Yoshizawa \& Saigusa, 2001; Hörnschemeyer, 2002; Hörnschemeyer \& Willkommen, 2007; Yoshizawa, 2007). On the other hand, Beutel et al. (in press) mentioned that the wing base characters involve a high degree of homoplasy, and this character system alone is insufficient to estimate the higher level phylogeny of Holometabola. However, my re-analyses of the data set provided by Beutel et al. (in press: supplement) revealed that the extremely low resolution from their independent analysis of the wing base characters is not due to high degree of homoplasy involved in this character system but mostly due to presence of many missing data by inclusion of the wingless taxa for the analysis (Boreidae of Mecoptera and Siphonaptera). The data set provided well resolved trees with several reasonably supported clades by exclusion of the wingless taxa from the analysis (personal examination and Beutel, pers. comm.).

One of the most important groups recovered by the present analyses is the Polyneoptera (Fig. 14). Morphologically, monophyly of Polyneoptera has been questioned (Hennig, 1966, 1981; Kristensen, 1991; Kukalova-Peck, 1991), and more informal term "lower Neoptera" has been proposed for Polyneoptera (Kristensen, 1991). Molecular data also recovered Polyneoptera as a paraphyletic group in many cases (Kjer, 2004; Yoshizawa \& Johnson, 2005; Misof et al., 2007; von Reumont et al., 2009), but its monophyly cannot be rejected because of extremely short interordinal branches (Whitfield \& Kjer, 2008). Only the most recent analyses of three nuclear protein-coding genes provided reasonable support for monophyly of Polyneoptera (Ishiwata et al., 2011). The present analyses revealed the following four autapomorphies of Polyneoptera from the wing base: 7 [1] humeral plate almost completely membranous on dorsal surface (ci and $\mathrm{ri}=1$, but reversed in some Blattodea); 14 [1] median notal wing process formed side-by-side articulation with $1 \mathrm{Ax}$ ( $\mathrm{ci}=0.50$, $\mathrm{ri}=0.80$, reversed in Blattodea); 15 [1] proximal tail of body of 1 Ax elongated and articulated with notum along long margin (non-homoplasious); 38 [1] Ba articulated with HP at point (highly homoplasious, $\mathrm{ci}=0.60$, ri $=0.50$ ). Monophyly of Polyneoptera was also supported by the total data, but no unambiguous support was obtained from the BG06 data (Fig. 15). Minet \& Bourgoin (1986: presence of the planturae: character 108 of BG01) and Grimaldi \& Engel (2005: fanlike anal lobe of the hindwing: character 49 of BG06) also have proposed potential autapomorphies of Polyneoptera. For both characters, reversals to the ancestral conditions in Embiodea, Zoraptera and/or Isoptera were assumed (Minet \& Bourgoin, 1986; Grimaldi \& Engel, 2005). In the tree obtained from the total data, Mystroptera (i.e., Embiodea + Zoraptera) was placed as the sister to all the remaining polyneopterans so that the character states identified by the above authors did not provide unambiguous support for monophyly of Polyneoptera (Fig. 15). Alternatively, except for 38 [2], the wing base autapomorphies of Polyneoptera were consistent even after inclusion of the wingless taxa in the analysis (Fig. 15). Therefore, for the first time, the present study has identified non-homoplasious morphological autapomorphies of Polyneoptera. 
Some supraordinal monophyletic groups also were identified by the present analyses which are generally concordant between the trees obtained from the wing base data and the total data. As suggested by Engel \& Grimaldi (2000), Rafael \& Engel (2006) and Yoshizawa (2007), monophyly of Embiodea + Zoraptera (= Mystroptera) was supported by both data sets with high Bremer support values (Figs 14,15). No above mentioned authors performed a numerical cladistic analysis based on the total morphological evidence, and thus, this present study provides the first support for Mystroptera based on formal cladistic procedures. Monophyly of Mystroptera was strongly supported by six apomorphies from the wing base (all non-homoplasious except for 25 [2]: Figs 14, 15 and Appendix 2: see also Yoshizawa, 2007 and Appendix 3). The total data also supported this clade, with two rather homoplasious apomorphies from the non-wing base characters. Although not included in the BG06 matrix, an additional non-homoplasious apomorphy for Embiodea + Zoraptera, reversed musculature of metafemora, has been identified (Engel \& Grimaldi, 2000). In contrast, highly specialized and simplified wings as observed in Embiodea and Zoraptera may cause morphological regressions to the wing base structure, as of the case for Isoptera (see below). However, all apomorphies supporting Embiodea + Zoraptera are highly specialized and uniquely derived character states. Independent acquisitions of a total of six apomorphies, with five non-homoplasious ones, are hard to accept, and monophyly of Mystroptera is highly plausible morphologically (Gullan \& Cranston, 2010). In contrast, molecular-based phylogenetic placements of these orders are highly problematic, mainly due to very unusual evolutionary trends in a frequently used rDNA marker of Zoraptera (Kjer, 2004; Yoshizawa \& Johnson, 2005; Kjer et al., 2006). Molecularbased test for monophyly of Mystroptera and their placement must be based on gene markers with no or little unusual evolutionary trends, yet analyses of three nuclear protein-coding genes still failed to provide a robust support for placement of Zoraptera (Ishiwata et al., 2011).

Both data sets (wing base and total data) supported monophyly of Orthopterida (= Orthoptera + Phasmatodea), with low (1 from the wing base only) to relatively high (4 from the total data) Bremer support values. Yoshizawa (2007) suggested a close relationship between Phasmatodea and Mystroptera on the basis of PNWP separated from the notum. However, the character state is observed also in Orthoptera, Holometabola, or even in Ephemeroptera, and thus cannot support Phasmatodea + Mystroptera (see also Appendix 3). The total data supported monophyly of Orthoptera by two general morphology characters (both nonhomoplasious). A potential autapomorphic wing base condition (13 [2] AmNWP placed over $1 \mathrm{Ax}$ ) was confirmed for Orthoptera, but this character state did not provide unambiguous support for the order because some species of Ensifera lack this apomorphic condition. In contrast, somewhat surprisingly, independent analysis of the wing base data resulted in paraphyletic Orthoptera, with Phasmatodea placed to be the sister to Caelifera. This relationship was supported by a conspicuous and non-homoplasious apomorphy, neck of 1 Ax desclerotized (18 [1]). Although monophyly of Orthoptera now is accepted generally (Kristensen, 1991; Grimaldi \& Engel, 2005; Gullan \& Cranston, 2010), a close relationship between Caelifera and Phasmatodea has been pointed out before (e.g. Sharov, 1968; Hennig, 1981). Analyses of 18S (Kjer, 2004; Yoshizawa \& Johnson, 2005) or more extensive multigene analyses (Kjer et al., 2006; Ishiwata et al., 2011) fail to provide strong support for Orthoptera: evidently orthopteran monophyly deserves further examination.

Almost the only polyneopteran supraordinal monophyletic group for which consensus 
has been achieved widely and consistently is the Dictyoptera (e.g., Hennig, 1969, 1981; Boudreaux, 1979; Kristensen, 1991; Haas \& Kukalova-Peck, 2001; Grimaldi \& Engel, 2005). The hindwing base structure provided two non-homoplasious apomorphies for Dictyoptera (Figs 14, 15): 24 [1] anterior articulation between 1Ax and 2Ax absent; 31 [2] 2Ax and PMP partly fused. In contrast, Isoptera apparently were misplaced by inclusion of the wing base characters. The results from both data sets placed Isoptera to be the sister to Blattodea + Mantodea, and the latter clade was supported by two wing base apomorphies (8 [2] and 22 [0]: Appendix 2) and one character from the BG06 data. However, monophyly of Blattodea + Isoptera is very widely accepted, or Isoptera are even considered to be a sub-clade within Blattodea, by many morphological, behavioral and molecular data (Lo et al., 2000; Grimaldi \& Engel, 2005; Inward et al., 2007). An abundance of regressive traits in Isoptera has been pointed out (Nutting, 1951; Kristensen, 1991) and, notably the hindwing of Isoptera is greatly modified and simplified compared to the fan-shaped hindwings as observed in Blattodea and Mantodea. The placement of Isoptera as estimated by inclusion of the wing base data is probably due to secondary reversal of the character system according to their reduced morphology.

Incongruence between the trees yielded from two data sets mainly concerns phylogenetic placements of Plecoptera and Dermaptera. The total morphology data placed Plecoptera to the sister to the rest of Polyneoptera excluding Mystroptera. Plecoptera sometimes have been considered to be the most "primitive" order of Neoptera (e.g., Matsuda, 1970; Kristensen, 1991; Hörnschemeyer, 2002); thus this placement might be regarded as reasonable. Dermaptera are placed by the total data to the sister of Dictyoptera. This placement received two apomorphies from the wing base data (4 [1] and 40 [1]), but both are highly homoplasious (Appendix 2). Dermaptera + Dictyoptera also was recovered by a previous analysis of the flight system, including the structures of the wing base (Haas \& Kukalova-Peck, 2001). However, the wing base synapomorphies identified by the study are highly questionable as follow (revised by Hörnschemeyer \& Wilkommen, 2007): 2Ax with arched proximal margin: the proximal margin of $2 \mathrm{Ax}$ is more or less arched in many orders (Figs 1-13), and I could not evaluate this ambiguous character state (see also Whiting \& Kathirithamby, 1995); PNWP desclerotized: as illustrated in Figs 2-5, PNWP clearly is identified in both Dermaptera and Dictyoptera. In contrast, when the wing base data were analyzed independently, monophyly of Plecoptera + Dermaptera was supported by two non-homoplasious apomorphies: 10 [1] ventral BSc with keel along anterior margin; 19 [1] anteroproximal corner of body of 1Ax with flap extending over AmNWP. Character 10 is a ventral structure, and its independence from the dorsal structures (characters 19) is highly probable. Although this clade received no support from the BG06 data, Kristensen $(1981,1991)$ listed the following possible synapomorphies of these orders: three segmented tarsi (rejected by palaeontological evidence: Grimaldi \& Engel, 2005); lack of male gonostyli; lack of functional ovipositor (these two character states are seen also in Embiodea and Zoraptera); paired male gonopore (maybe plesiomorphy: see also Kamimura, 2004). Although generally weakly supported, molecular phylogenies have recovered this relationship frequently (Kjer, 2004; Yoshizawa \& Johnson, 2005; Misof et al., 2007; Ishiwata et al., 2011), and thus the possibility of Plecoptera + Dermaptera is worth consideration.

Phylogenetic relationships among the above-identified supraordinal clades were only 
poorly resolved: analyses of different data sets (wing base and total data) provided different relationships, with Bremer support value of 1 or less. These should await future study.

The wing base characters do not provide any information for the phylogenetic placements of the wingless orders. Furthermore, inclusion of a lot of wing base characters even provides many missing data for the wingless insects, which may decrease stability of tree estimations (Platnick et al., 1991; Novacek, 1992; Beutel et al., in press). Nevertheless, the result from the total data were not altered by inclusion of the wingless orders: i.e., the analysis of the total data (+wingless) yielded two equally parsimonious trees that are completely concordant with that obtained from the analysis of the winged orders, with two possible placements for Grylloblattodea + Mantophasmatodea (arrows in Fig. 15). An independent analysis of the BG06 data including both winged and wingless orders yielded 27 equally parsimonious trees (not shown), with $\mathrm{CI}=0.70$ and $\mathrm{RI}=0.63$ (the latter value is lower than that obtained from the wing base + BG06 data). Therefore, inclusion of the wing base characters stabilized the tree estimation even if the wingless taxa are included in the analysis. Clearly addition of the wing base data is valuable for more stable estimations of the phylogenetic placements of the wingless taxa, because such data can provide more robust "backbone support" for the winged orders.

Although not a main subject of the present study, the following wing base characters were identified as autapomorphies of Neoptera by the present analyses (Figs 14, 15): 1 [1] presence of folding lines other than basal hinge; 3 [1] fusion of MNWP with notum; 6 [1] humeral plate expanded ventrally; 8 [1] humeral plate tightly associated with ventral BSc (reversed in Orthoptera and Phasmatodea); 29 [1] presence of internal ligament of 2Ax; 31 [1] 2Ax separated from PMP; 35 [1] separation of PMP and DMP; 37 [1] basalare restricted to ventral region. Interpretations of the polarity of these characters depend on the phylogeny of "Palaeoptera" (Willkommen \& Hörnschemeyer, 2007), because a monophyletic Palaeoptera will render uncertain the polarity of these characters. The Polyneoptera problem is not resolved, yet (Ogden \& Whiting, 2003), but some recent analyses tend to reject monophyly of "Palaeoptera" (Soldán, 1997; Kjer, 2004; Misof et al., 2007; Simon et al., 2009; von Reumont et al., 2009: but see also Ishiwata et al., 2011). Identification of the sister taxon of Neoptera also is an unresolved problem (Ogden \& Whiting, 2003; Whitfield \& Kjer, 2008) but, under the paraphyletic "Polyneoptera", interpretations for the polarity of these characters are consistent. Willkommen \& Hörnschemeyer (2007) considered the separated axillary sclerites as observed in Neoptera to be a plesiomorphic condition within Pterygota but, at least 2Ax, PMP and DMP are concerned, their unseparated condition is better considered to be plesiomorphic. In contrast, the fusion of MNWP with the notum is considered here to be an autapomorphy of Neoptera (Yoshizawa \& Ninomiya, 2007; Ninomiya \& Yoshizawa, 2009).

As discussed above, significant levels of homoplasy were identified in the wing base characters, and Isoptera obviously were misplaced by inclusion of the wing base data. Therefore, structures of the wing base apparently are not a panacea for the higher systematics of the winged insects. However, as discussed above, the present examinations provided further evidence that the wing base structure is an information rich, less homoplasious, and valuable character system in estimating deep insect phylogeny (Yoshizawa \& Saigusa, 2001; Hörnschemeyer, 2002; Hörnschemeyer \& Willkommen, 2007; Yoshizawa, 2007). Some branches recovered by the present analyses (e.g., Plecoptera + Dermaptera) contradict with the 
results from other morphological studies (Beutel \& Gorb, 2001, 2006; Grimaldi \& Engel, 2005), but such clades have also received some supports from other morphological data, too (Kristensen, 1991; Grimaldi \& Engel, 2005: Fig. 15). In addition, the trees presented here are highly congruent with the recent results from the molecular data in some points (e.g., Dictyoptera, Plecoptera + Dermaptera, Paraneoptera + Holometabola: Kjer, 2004; Yoshizawa \& Johnson, 2005; Ishiwata et al., 2011), providing an additional support for the usefulness of this character system. Most importantly, monophyly of Polyneoptera was consistently supported by inclusion of the wing base characters, which have provided the first unambiguous morphological support for this problematic supraordinal group.

Additional Supporting Information can be found in the online version of this article under the DOI reference: DOI: $X X . X X X X / j . X X X X-X X X X . X X X X . X X X X X . X$

SI. Data matrix of the total data set (wing base + Beutel \& Gorb, 2006) including wingless taxa

\section{Acknowledgments}

I thank Gen Ito, Klaus-D. Klass, Shigeyuki Koshikawa, Charles Lienhard, Yuta Mashimo, Masahiro Ôhara, Akiko Otsuki, Shigekazu Uchida and Toyohei Saigusa for supplying very valuable specimens for this study; G. Ito and A. Otsuki for identification of specimens; and A. Otsuki, Peter Cranston and an anonymous reviewer for helpful comments to improve the manuscript.

\section{References}

Beutel, R. G., Friedrich, F., Hörnchemeyer, T., Pohl, H., Hünefeld, F., Beckmann, F., Meier, R., Misof, B., Whiting, M. F. \& Vihelmsen, L. (in press) Morphological and molecular evidence converge upon a robust phylogeny of the megadiverse Holometabola. Cladistics doi: 10.111/j.1096-0031.2010.00338x.

Beutel, R. G. \& Gorb, S. N. (2001) Ultrastructure of attachment specialization of hexapods (Arthropoda): evolutionary patterns inferred from a revised ordinal phylogeny. Journal of the Zoological Systematics and Evolutionary Research, 39, 177-277.

Beutel, R. G. \& Gorb, S. N. (2006) A revised interpretation of the evolution of attachment structures in Hexapoda with special emphasis on Mantophasmatodea. Arthropod Systematics \& Phylogeny, 64, 3-25.

Bininda-Emonds, O. R. P., Bryant, H. N. \& Russell, A. P. (1998) Supraspecific taxa as terminals in cladistic analysis: implicit assumptions of monophyly and a comparison of methods. Biological Journal of the Linnean Society, 64, 101-133.

Boudreaux, H. B. (1979) Arthropod Phylogeny with Special Reference to Insects. John Wiley \& Sons, Inc., NY.

Brodsky, A.K. (1994) The Evolution of Insect Flight. Oxford University Press, NY. Engel, M.S. \& Grimaldi, D. A. (2000) A winged Zorotypus in Miocene amber from the Dominican Republic (Zoraptera: Zorotypidae), with discussion on relationships of and within the order. Acta Geológica Hispánica, 35, 149-164.

Grimaldi, D. \& Engel, M.S. (2005) Evolution of the Insects. Cambridge University Press, Cambridge. 
Gullan, P. J. \& Cranston, P. S. (2010) The Insects: An Outline of Entomology, 4th edn. John Wiley \& Sons Ltd., Oxford.

Haas, F. \& Kukalová-Peck, J (2001) Dermaptera hindwing structure and folding: New evidence for familial, ordinal and superordinal relationships within Neoptera (Insecta).

European Journal of Entomology, 98, 445-509.

Hennig, W. (1966) Phylogenetic Systematics. University of Illinois Press, Urbana.

Hennig, W. (1981) Insect Phylogeny. John Wiley \& Sons, Chichester.

Hörnschemeyer, T. (2002) Phylogenetic significance of the wing-base of the Holometabola (Insecta). Zoologica Scripta, 31, 19-27.

Hörnschemeyer, T. \& Willkommen, J. (2007) The contribution of flight system characters to the reconstruction of the phylogeny of the Pterygota. Arthropod Systematics \& Phylogeny, 65, $15-23$.

Inward, D., Beccaloni, G. \& Eggleton, P. (2007) Death of an order: a comprehensive molecular phylogenetic study confirms that termites are eusocial cockroaches. Biology Letters, $\mathbf{3}$, 331-335.

Ishiwata, K., Sasaki, G., Ogawa, J., Miyata, T. \& Su, Z-H. (2011) Phylogenetic relationships among insect orders based on three nuclear protein-coding gene sequences. Molecular Phylogenetics and Phylogeny, 58, 169-180.

Jamieson, B. G. M., Dallai, R. \& Afzelius, B. A. (1999) Insects. Their Spermatozoa and Phylogeny. Science Publishers Inc., NH.

Kamimura, Y. (2004) In search of the origin of twin penises: Molecular phylogeny of earwigs (Dermaptera: Forficulina) based on mitochondrial and nuclear ribosomal RNA genes. Annals of the Entomological Society of America, 97, 903-912.

Kjer, K. M. (2004) Aligned 18S and insect phylogeny. Systematic Biology, 53, 506-514.

Kjer, K. M., Carle, F. L., Litman, J. \& Ware, J. (2006) A molecular phylogeny of Hexapoda. Arthropod Systematics and Phylogeny, 64, 35-44.

Kristensen, N.P. (1991) Phylogeny of extant hexapods. The Insects of Australia. A Textbook for Students and Research Workers. Vol. I, 2nd edn (ed. by I. D. Naumann, P. B. Carne, J. F. Lawrence, E. S. Nielsen, J. P. Spradbery, R. W. Taylor, M. J. Whitten \& M. J. Littlejohn), pp. 125-140. Melbourne University Press, Carlton, Victoria.

Kukalová-Peck, J. (1991) Fossil history and the evolution of hexapod structures. The Insects of Australia. A Textbook for Students and Research Workers. Vol. I, 2nd edn (eds. I. D.

Naumann, P. B. Carne, J. F. Lawrence, E. S. Nielsen, J. P. Spradbery, R. W. Taylor, M. J. Whitten \& M. J. Littlejohn), pp. 141-179. Melbourne University Press, Carlton, Victoria. Lo, N., Tokuda, G., Watanabe, H., Rose, H., Slaytor, M., Maekawa, K., Bandi, C. \& Noda, H. 2000. Evidence from multiple gene sequences indicates that termites evolved from woodfeeding cockroaches. Current Biology, 10, 801-804.

Maddison, D. R. \& Maddison, W. P. (2001) MacClade 4: Analysis of Phylogeny and Character Evolution. Sinauer, MA.

Matsuda, R. (1970) Morphology and evolution of the insect thorax. Memoirs of the Entomological Society of Canada, 76, 1-431.

Minet, J. \& Bourgoin, T. (1986) Phylogenie et classification des Hexapodes (Arthropoda). Cahiers Liaison, OPIE, 20, 23-28.

Misof, B., Niehuis, O., Bischoff, I., Rickert, A., Erpenbeck, D. \& Staniczek, A. (2007) 
Towards an 18S phylogeny of hexapods: Accounting for group-specific character covariance in optimized mixed nucleotide/doublet models. Zoology, 110, 409-429.

Morgai, M. J. \& Kelchner, S. A. (2010) Inference of molecular homology and sequence alignment by direct optimization. Molecular Phylogenetics and Evolution, 56, 305-311.

Ninomiya, T. \& Yoshizawa, K. (2009) A revised interpretation of the wing base structure in Odonata. Systematic Entomology, 34, 334-345.

Novacek, M. J. (1992) Fossils as critical data for phylogeny. Extinction and Phylogeny (eds by Q. D. Wheeler \& M. J. Novacek), pp. 46-86. Columbia University Press, New York.

Nutting, W. L. (1951) A comparative anatomical study of the heart and accessory structures of the orthopteroid insects. Journal of Morphology, 89, 501-597.

Ogden, T. H. \& Whiting, M. F. (2003) The problem with "the Paleoptera Problem"; sense and sensitivity. Cladistics, 19, 432-442.

Platnick, N. I., Griswold, C. E. \& Coddington, J. A. (1991) On missing entries in cladistic analysis. Cladistics 7, 337-343.

Rafael, J. A. \& Engel, M. S. (2006) A new species of Zorotypus from Central Amazonia, Brazil (Zoraptera: Zrotypidae). American Museum Novitates, 3528, 1-11.

Rieppel, O. \& Kearney, M. (2002) Similarity. Biological Journal of the Linnean Society, 75, 59-82.

Ross, E. S. 2000. Embia: Contributions to the biosystematics of the insect order Embiidina.

Parts 1. Origin, relationships and integumental anatomy of the insect order Embiidina; Part 2. A review of the biology of Embiidina. Occasional papers of the California Academy of Science, 149, 1-89.

Sharov, A. G. (1968) Phylogeny of orthopteroid insects. Trudy Paleontologischeskogo Instituta Akademii Nauk, SSSR, 118, 1-216.

Simmons, M. P. (2004) Independence of alignment and tree search. Molecular Phylogenetics and Evolution, 31, 874-879.

Simon, S., Strauss, S., von Haeseler, A. \& Hadrys, H. (2009) A phylogenomic approach to resolve the basal pterygote divergence. Molecular Biology and Evolution, 26, 2719-2730.

Soldán, T. (1997) The Ephemeroptera: Whose sister-group are they? Ephemeroptera \& Plecoptera: Biology-Ecology-Systematics. (ed. by Landolt, P. \& Sartori, M.), pp. 514-519, Mauron + Tinguely \& Lachat, Fribourg.

Sorenson, M. D. \& Franzosa, E. A. (2007) TreeRot, version 3. Boston University, Boston, MA.

Swofford, D. L. (2002) PAUP*. Phylogenetic Analysis Using Parsimony (* and Other Methods), Version 4. Sinauer, MA.

Terry, M. D. \& Whiting, M. F. (2005) Mantophasmatodea and phylogeny of the lower neopterous insects. Cladistics, 21, 240-257.

Wheeler, W. C., Whiting, M., Wheeler, Q. D. \& Carpenter, J. M. (2001) The phylogeny of the extant hexapod orders. Cladistics, 17, 113-169.

Whitfield, J. B. \& Kjer, K. M. (2008) Ancient rapid radiations of insects: challenges for phylogenetic analysis. Annual Review of Entomology, 53, 449-472.

Whiting, M. F. \& Kathirithamby, J. (1995) Strepsiptera do not share hind wing venational synapomorphies with Coleoptera: A reply to Kukalová-Peck and Lawrence. Journal of New York Entomological Society, 103, 1-14. 
Willkommen, J. \& Hörnschemeyer, T. (2007) The homology of wing base sclerites and flight muscles in Ephemeroptera and Neoptera and the morphology of the pterothorax of Habroleptoides confusa (Insecta: Ephemeroptera: Leptophlebiidae). Arthropod Structure and Development, 36, 253-269.

Wootton, R. J. (1979) Function, homology and terminology in insect wings. Systematic Entomology, 4, 81-93.

von Reumont, B. M., Meusemann, K., Szucsich, N. U., Dell'Ampio, E., Gowri-Shankar, V., Bartel, D., Simon, S., Letsch, H. O., Stocsits, R. R., Luan, Y-X., Wägele, J. W., Pass, G., Hadrys, H. \& Misof, B. (2009) Can comprehensive background knowledge be incorporated into substitution models to improve phylogenetic analyses? A case study on major arthropod relationships. BMC Evolutionary Biology, 9, 119.

Yoshizawa, K. (2007) The Zoraptera problem: evidence for Zoraptera + Embiodea from the wing base. Systematic Entomology, 32, 197-204.

Yoshizawa, K. (2010) Direct optimization overly optimizes data. Systematic Entomology, 35, 199-206.

Yoshizawa, K. (2011) Problems in direct optimization. Taxa, Proceedings of the Japanese Society of Systematic Zoology, 30, 17-29 (in Japanese).

Yoshizawa, K. \& Johnson, K. P. (2005) Aligned 18S for Zoraptera (Insecta): Phylogenetic position and molecular evolution. Molecular Phylogenetics and Evolution, 37, 572-580.

Yoshizawa, K. \& Ninomiya, T. (2007) Homology of the wing base sclerites in Ephemeroptera (Insecta: Pterygota): a reply to Willkommen \& Hörnschemeyer. Arthropod Structure and Development, 36, 277-279.

Yoshizawa, K. \& Saigusa, T. (2001) Phylogenetic analysis of paraneopteran orders (Insecta: Neoptera) based on forewing base structure, with comments on monophyly of Auchenorrhyncha (Hemiptera). Systematic Entomology, 26, 1-13. 


\section{Appendix 1. Taxa examined}

Odonata and Ephemeroptera: See Yoshizawa \& Ninomiya (2007) and Ninomiya \& Yoshizawa (2009)

Plecoptera: Gripopterygidae: Illiesoperla, Trinotoperla; Notonemouridae: Austrocercella; Capniidae: Capnia; Nemouridae: Nemoura; Pteronarcyidae: Pteronarcys; Chloroperlidae: Alloperla; Perlidae: Kamimuria, Oyamia; Perlodidae: Isoperla.

Dermaptera: Diplatydae: Diplatys; Spongiphoridae: Labia; Labiduridae: Labidura; Forficulidae: Timomenus.

Mantodea: Acromantidae: Acromantis; Amorphoscelidae: Amorphoscelis; Hymenopodidae:

Creobroter; Mantidae: Mantis, Satilia, Tenodera; Metallyticidae: Metallyticus.

Blattodea: Derocalymmidae: Trichoblatta; Hemeogamiidae: Eucorydia; Pycnoscelidae:

Pycnoscelis; Blattidae: Periplaneta; Epilampridae: Rhabdoblatta.

Isoptera: Mastotermidae: Mastotermes; Rhinotermitidae: Coptotermes, Reticulitermes;

Termopsidae: Hodotermopsis; Termitidae: Nasutitermes, Pericapritermes.

Embiodea: Clothodidae: Antipaluria; Oligotomidae: Oligotoma.

Zoraptera: Zorotypidae: Zorotypus.

Phasmatodea: Phasmatidae: Micadina, Sipyloidea; Phylliidae: Phyllium; Pseudophasmatidae: Pseudophasma (from Matsuda 1970).

Orthoptera: Ensifera: Gryllidae: Truljalia; Gryllotalpidae: Gryllotalpa; Tettigoniidae: Chizuella, Eobiana, Euconocephalus, Mecopoda, Phaneroptera, Ruspolia; Caelifera: Acrididae: Acrida, Aiolopus, Chorthippus, Formosacris, Glyptobothrus, Mecostethus, Oedaleus, Phlaeoba, Trilophidia; Chorotypidae: Erianthella; Pyrgomorphidae: Atractomorpha, Aularches; Tetrigidae: Criotettix, Eucriotettix, Tetrix; Tridactylidae: Tridactys.

Psocodea: Prionoglarididae: Neotrogla; Psocidae: Longivalvus.

Megaloptera: Corydalidae: Protohermes, Parachauliodes, Neochauliodes; Sialidae: Sialis

Mecoptera: Bittacidae: Bittacus; Panorpidae: Panorpa. 
Appendix 2. Characters scored in the wing base data set.

- Character 1. Folding lines: (0) basal hinge only; (1) with additional folding lines (ci=1.00, $\mathrm{ri}=1.00$ by wing base data; $\mathrm{ci}=1.00, \mathrm{ri}=1.00$ by total data).

- Character 2. Antemedian notal wing process: (0) not clearly differentiated; (1) well developed ( $\mathrm{ci}=0.50, \mathrm{ri}=0.67$ by wing base data; $\mathrm{ci}=0.33, \mathrm{ri}=0.33$ by total data).

- Character 3. Median notal wing process: (0) separated from notum; (1) fused to notum ( $\mathrm{ci}=1.00, \mathrm{ri}=1.00$ by wing base data; $\mathrm{ci}=1.00, \mathrm{ri}=1.00$ by total data).

- Character 4. Posterior notal wing process: (0) separated from notum; (1) fused to notum ( $\mathrm{ci}=0.33$, ri $=0.60$ by wing base data; $\mathrm{ci}=0.33, \mathrm{ri}=0.60$ by total data).

- Character 5. Tegula: (0) membranous or less developed; (1) strongly sclerotized (ci=1.00, $\mathrm{ri}=1.00$ by wing base data; $\mathrm{ci}=1.00, \mathrm{ri}=1.00$ by total data).

- Character 6 . Humeral plate, ventral: (0) not sclerotized; (1) sclerotized (ci=1.00, ri=1.00 by wing base data; $\mathrm{ci}=1.00, \mathrm{ri}=1.00$ by total data).

- Character 7. Humeral plate, dorsal: (0) sclerotized; (1) membranous (ci=1.00, ri=1.00 by wing base data; $\mathrm{ci}=1.00, \mathrm{ri}=1.00$ by total data).

- Character 8 . Humeral plate and ventral basisubcostale: (0) widely separated; (1) closely associated; (2) fused ( $\mathrm{ci}=0.67$, ri $=0.80$ by wing base data; $\mathrm{ci}=0.67, \mathrm{ri}=0.80$ by total data).

- Character 9. Humeral plate and dorsal basisubcostale: (0) separated; (1) fused (ci=1.00, ri=0 by wing base data; $\mathrm{ci}=1.00$, ri=0 by total data).

- Character 10. Anterior margin of ventral basisubcostale: (0) normal; (1) with keel along anterior margin ( $\mathrm{ci}=1.00, \mathrm{ri}=1.00$ by wing base data; $\mathrm{ci}=0.50$, $\mathrm{ri}=0$ by total data).

- Character 11. Basal hinge: (0) running between posterior notal wing process and 3Ax; (1) running between notum and posterior notal wing process $(\mathrm{ci}=1.00, \mathrm{ri}=0$ by wing base data; $\mathrm{ci}=1.00, \mathrm{ri}=0$ by total data).

- Character 12. Articulation between anterior notal wing process and $1 \mathrm{Ax}$ : (0) almost at a point; (1) along long margin of neck of $1 \mathrm{Ax}(\mathrm{ci}=0.50, \mathrm{ri}=0.50$ by wing base data; $\mathrm{ci}=0.50, \mathrm{ri}=0.50$ by total data).

- Character 13. Articulation between antemedian notal wing process and 1Ax: (0) absent; (1) present, side-by-side; (2) present, AmNWP placed over $1 \mathrm{Ax}$ ( $\mathrm{ci}=0.33$, ri $=0.20$ by wing base data; $\mathrm{ci}=0.29$, ri $=0$ by total data).

- Character 14. Median notal wing process and body of 1Ax: (0) median notal wing process placed over 1Ax; (1) side-by-side; (2) 1 Ax placed over median notal wing process $(\mathrm{ci}=0.50$, $\mathrm{ri}=0.80$ by wing base data; $\mathrm{ci}=0.50, \mathrm{ri}=0.80$ by total data).

- Character 15. Proximal tail of body of 1Ax: (0) short; (1) long, articulated with median notal wing process along long margins; (2) long, articulated with median notal wing process at a point ( $\mathrm{ci}=1.00, \mathrm{ri}=1.00$ by wing base data; $\mathrm{ci}=1.00, \mathrm{ri}=1.00$ by total data).

- Character 16. 1Ax and posterior notal wing process: (0) separated; (1) fused (ci=1.00, ri=1.00 by wing base data; $\mathrm{ci}=1.00, \mathrm{ri}=1.00$ by total data).

- Character 17. Head of 1Ax: (0) normal; (1) enlarged (ci=1.00, ri=1.00 by wing base data; $\mathrm{ci}=1.00, \mathrm{ri}=1.00$ by total data).

- Character 18. Neck of 1Ax: (0) sclerotized; (1) membranous (ci=1.00, ri=1.00 by wing base data; $\mathrm{ci}=0.50, \mathrm{ri}=0$ by total data).

- Character 19. Anteroproximal corner of body of 1Ax: (0) without flap; (1) with flap forming 
socket-like structure extending over antemedian notal wing process $(\mathrm{ci}=1.00, \mathrm{ri}=1.00$ by wing base data; $\mathrm{ci}=0.50, \mathrm{ri}=0$ by total data).

- Character 20. Articulation between 1Ax and basisubcostale: (0) present; (1) absent (ci=1.00, ri $=0$ by wing base data; $\mathrm{ci}=1.00$, ri $=0$ by total data).

- Character 21. 1Ax and basiradiale: (0) separated; (1) partly fused ( $\mathrm{ci}=1.00$, ri=0 by wing base data; $\mathrm{ci}=1.00, \mathrm{ri}=0$ by total data).

- Character 22. Basiradiale and head of 1Ax: (0) not articulated; (1) articulated (ci=0.50, ri $=0.75$ by wing base data; $\mathrm{ci}=0.33$, ri $=0.50$ by total data).

- Character 23. $1 \mathrm{Ax}$ and 2Ax: (0) fused; (1) separated ( $\mathrm{ci}=1.00$, ri=0 by wing base data; $\mathrm{ci}=1.00, \mathrm{ri}=0$ by total data).

- Character 24. 1Ax and anteroproximal corner of 2Ax: (0) closely related; (1) separated by membrane ( $\mathrm{ci}=1.00, \mathrm{ri}=1.00$ by wing base data; $\mathrm{ci}=1.00, \mathrm{ri}=1.00$ by total data).

- Character 25. Bending region of basiradiale: (0) broad; (1) constricted; (2) membranous ( $\mathrm{ci}=1.00, \mathrm{ri}=1.00$ by wing base data; $\mathrm{ci}=1.00, \mathrm{ri}=1.00$ by total data).

- Character 26. Basiradiale, distal to convex axillary folding line: (0) without membranous region; (1) with membranous region ( $\mathrm{ci}=0.50$, ri $=0.50$ by wing base data; $\mathrm{ci}=1.00, \mathrm{ri}=1.00$ by total data).

- Character 27. Basisubcostale and 2Ax: (0) widely separated by basiradiale; (1) closely approximated ( $\mathrm{ci}=1.00, \mathrm{ri}=0$ by wing base data; $\mathrm{ci}=1.00, \mathrm{ri}=0$ by total data).

- Character 28. 2Ax: (0) flat; (1) swollen dorsally ( $\mathrm{ci}=1.00$, ri=0 by wing base data; $\mathrm{ci}=1.00$, ri $=0$ by total data).

- Character 29. Internal ligament of 2Ax: (0) absent; (1) present ( $\mathrm{ci}=1.00, \mathrm{ri}=1.00$ by wing base data; $\mathrm{ci}=1.00, \mathrm{ri}=1.00$ by total data).

- Character .30 Ligament of 2Ax: (0) medially; (1) on posterior end ( $\mathrm{ci}=1.00$, ri=1.00 by wing base data; $\mathrm{ci}=1.00, \mathrm{ri}=1.00$ by total data).

- Character 31. 2Ax and proximal median plate: (0) completely fused; (1) partly fused; (2) completelyseparated ( $\mathrm{ci}=1.00, \mathrm{ri}=1.00$ by wing base data; $\mathrm{ci}=1.00, \mathrm{ri}=1.00$ by total data).

- Character 32. Position of proximal median plate: (0) distal to $2 \mathrm{Ax}$; (1) posterodistal to $2 \mathrm{Ax}$ ( $\mathrm{ci}=1.00, \mathrm{ri}=0$ by wing base data; $\mathrm{ci}=1.00, \mathrm{ri}=0$ by total data).

- Character 33. Proximal median plate: (0) evenly sclerotized; (1) sclerotization of distal margin much stronger ( $\mathrm{ci}=1.00, \mathrm{ri}=0$ by wing base data; $\mathrm{ci}=1.00, \mathrm{ri}=0$ by total data).

- Character 34. Proximal median plate: (0) well sclerotized; (1) largely membranous anteriorly; (2) largely membranous proximally ( $\mathrm{ci}=0.67, \mathrm{ri}=0.67$ by wing base data; $\mathrm{ci}=0.67, \mathrm{ri}=0.67$ by total data).

- Character 35. Proximal and distal median plates: (0) fused; (1) separated (ci=1.00, ri=1.00 by wing base data; $\mathrm{ci}=1.00, \mathrm{ri}=1.00$ by total data).

- Character 36. Distal median plate: (0) well sclerotized; (1) largely membranous (ci=0.50, ri=0 by wing base data; $\mathrm{ci}=0.50$, ri $=0$ by total data).

- Character 37. Position of basalare: (0) extended over dorsal region; (1) restricted to ventral region ( $\mathrm{ci}=1.00, \mathrm{ri}=1.00$ by wing base data; $\mathrm{ci}=1.00, \mathrm{ri}=1.00$ by total data).

- Character 38. Articulation between basalare and humeral plate: (0) along broad margins; (1) at a point; (2) loosely related; (3) completely absent ( $\mathrm{ci}=0.60$, $\mathrm{ri}=0.50$ by wing base data; $\mathrm{ci}=0.60$, $\mathrm{ri}=0.50$ by total data).

- Character 39. Articulation between basalare and ventral basisubcostale: (0) absent; (1) present 
( $\mathrm{ci}=0.50, \mathrm{ri}=0.50$ by wing base data; $\mathrm{ci}=1.00, \mathrm{ri}=1.00$ by total data).

- Character 40. Posterior corner of basalare: (0) not strongly swelling; (1) strongly swelling ( $\mathrm{ci}=0.25$, ri $=0.50$ by wing base data; $\mathrm{ci}=0.33, \mathrm{ri}=0.67$ by total data)

- Character 41. Pleural wing process: (0) articulated with ventral 2Ax: (1) articulated with ventral $\mathrm{BSc}$ ( $\mathrm{ci}=1.00, \mathrm{ri}=0$ by wing base data; $\mathrm{ci}=1.00, \mathrm{ri}=0$ by total data)

Appendix 3. Corrections to the previous misinterpretations proposed by Yoshizawa

- Dorsal humeral plate of Plecoptera illustrated by Yoshizawa \& Saigusa (2001) and Yoshizawa (2007), and that of Dermaptera, Embiodea, Isoptera and Phasmatodea illustrated by Yoshizawa (2007) are either not homologous with the humeral plate (see Fig. 1) or misinterpretation of the ventral sclerite as dorsal one.

- The humeral plate presents on ventral surface in Zoraptera (see Fig. 10), although Yoshizawa (2007) stated its absence as an autapomorphy of the order.

- In Yoshizawa (2007), 2Ax of Phasmatodea was illustrated as a very narrow structure, but unlabelled sclerite illustrated just anterior to $2 \mathrm{Ax}$ (fig. 2C) actually represents a part of $2 \mathrm{Ax}$, and they are not divided by a membranous region (Fig. 8).

- Yoshizawa (2007) stated that the posterior notal wing process of Embiodea is always separated from the notum, but they are fused with each other for sometimes, at least in Clothoidae (Fig. 9). See also Matsuda (1970: fig. 50) and Ross (2000: fig. 33). 


\section{Figure Captions}

Fig. 1. The hindwing base of Illiesoperla australis (Plecoptera), showing dorsal (A: head comes to the top) and ventral (B: head comes to the left) structures. See Materials and Methods for abbreviations.

Fig. 2. The hindwing base of Labidula riparia (Dermaptera), showing dorsal (A) and ventral (B) structures.

Fig. 3. The hindwing base of Eucorydia yasumatsui (Blattodea), showing dorsal (A) and ventral (B) structures.

Fig. 4. The hindwing base of Metallyticus sp. (Mantodea), showing dorsal (A) and ventral (B) structures.

Fig. 5. The hindwing base of Mastotermes darwiniensis (Isoptera), showing dorsal (A) and ventral (B) structures.

Fig. 6. The hindwing base of Homorocoryphus ineosus (Orthoptera: Ensifera), showing dorsal (A) and ventral (B) structures.

Fig. 7. The hindwing base of Acrida cinerea (Orthoptera: Caelifera), showing dorsal (A) and ventral (B) structures.

Fig. 8. The hindwing base of Sipyloidea sipylus (Phasmatodea), showing dorsal (A) and ventral (B) structures.

Fig. 9. The hindwing base of Antipaluria urichii (Embiodea), showing dorsal (A) and ventral (B) structures.

Fig. 10. The hindwing base of Zorotypus sp.MY1 (Zoraptera), showing dorsal (A) and ventral (B) structures.

Fig. 11. The hindwing base of Neotrogla (Psocodea), showing dorsal (A) and ventral (B) structures.

Fig. 12. The hindwing base of Sialis sp. (Megaloptera), showing dorsal (A) and ventral (B) structures.

Fig. 13. The hindwing base of Panorpa pryeri (Mecoptera), showing dorsal (A) and ventral (B) structures.

Fig. 14. Maximum parsimony tree estimated from the independent wing base data. Black bars associated with numbers indicate character and character state change reconstructed on the branches. Numbers in circles indicate Bremer support values.

Fig. 15. Maximum parsimony tree estimated from the total morphology data, with parsimonious character reconstruction on the tree. Black bars associated with numbers indicate the wing base character and character state changes reconstructed on the branches. Gray bars indicate apomorphies from the data used by Beutel \& Gorb (2006). Numbers in white circles indicate Bremer support values as calculated from the total data set excluding the wingless orders. Arrows indicate two estimated positions of Grylloblattodea + Mantophasmatodea as estimated from the total data set including the wingless orders, and Bremer support values obtained from the data set are shown as numbers in black circles.

ADD Supporting Information file for datamatrix

SI. Data matrix of the total data set (wing base + Beutel \& Gorb, 2006) including wingless taxa 


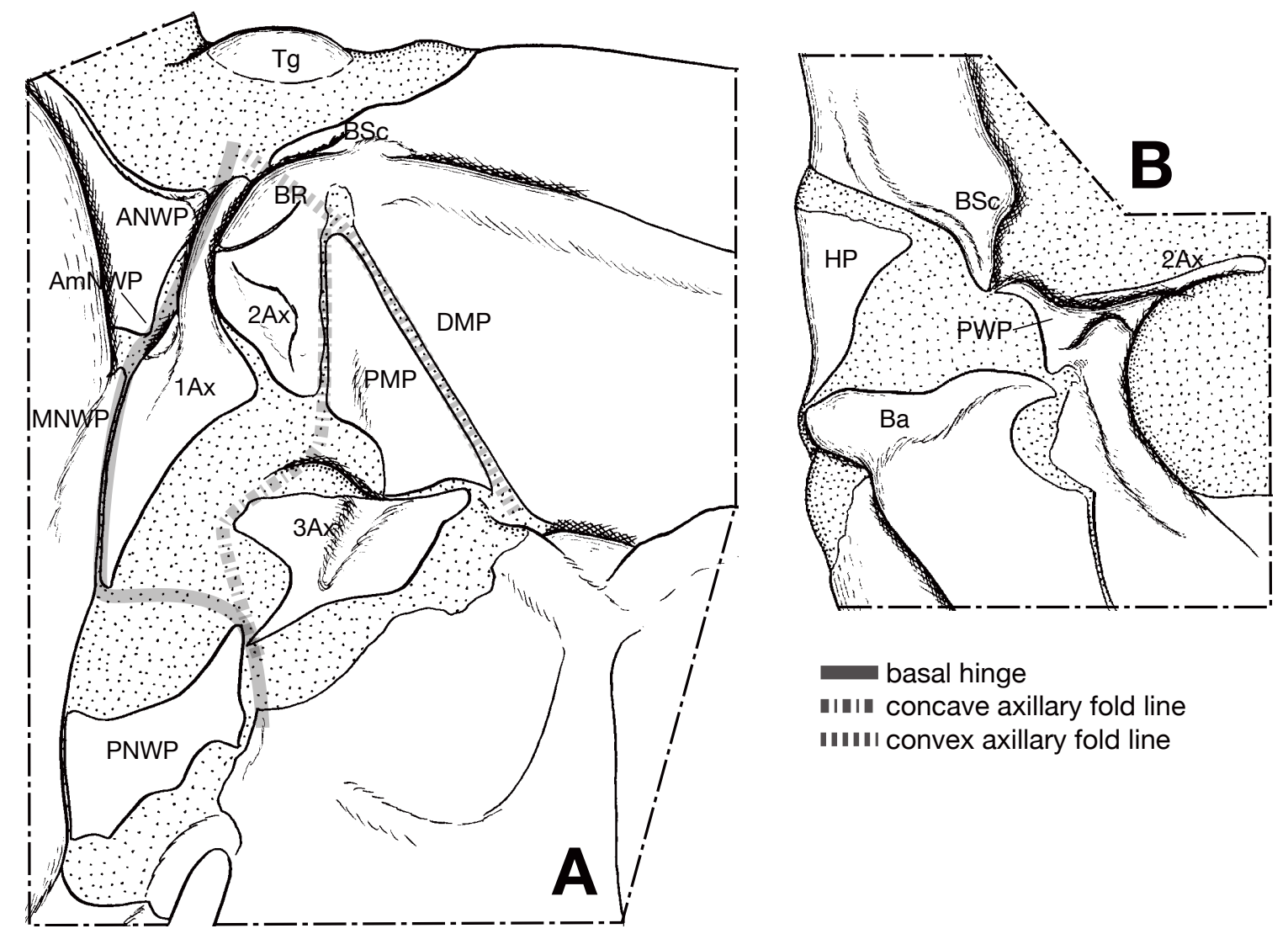



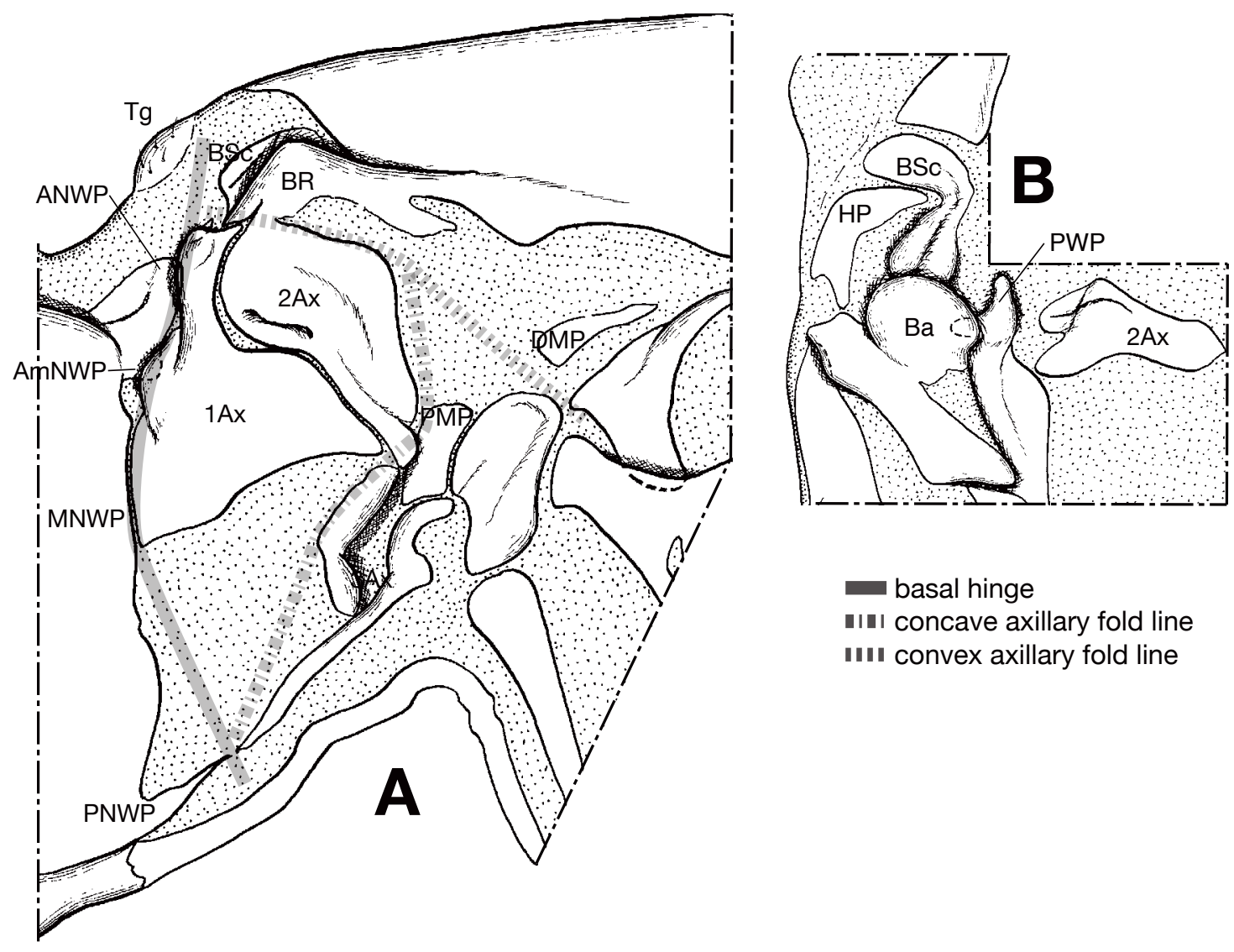

basal hinge

-II concave axillary fold line u u convex axillary fold line 


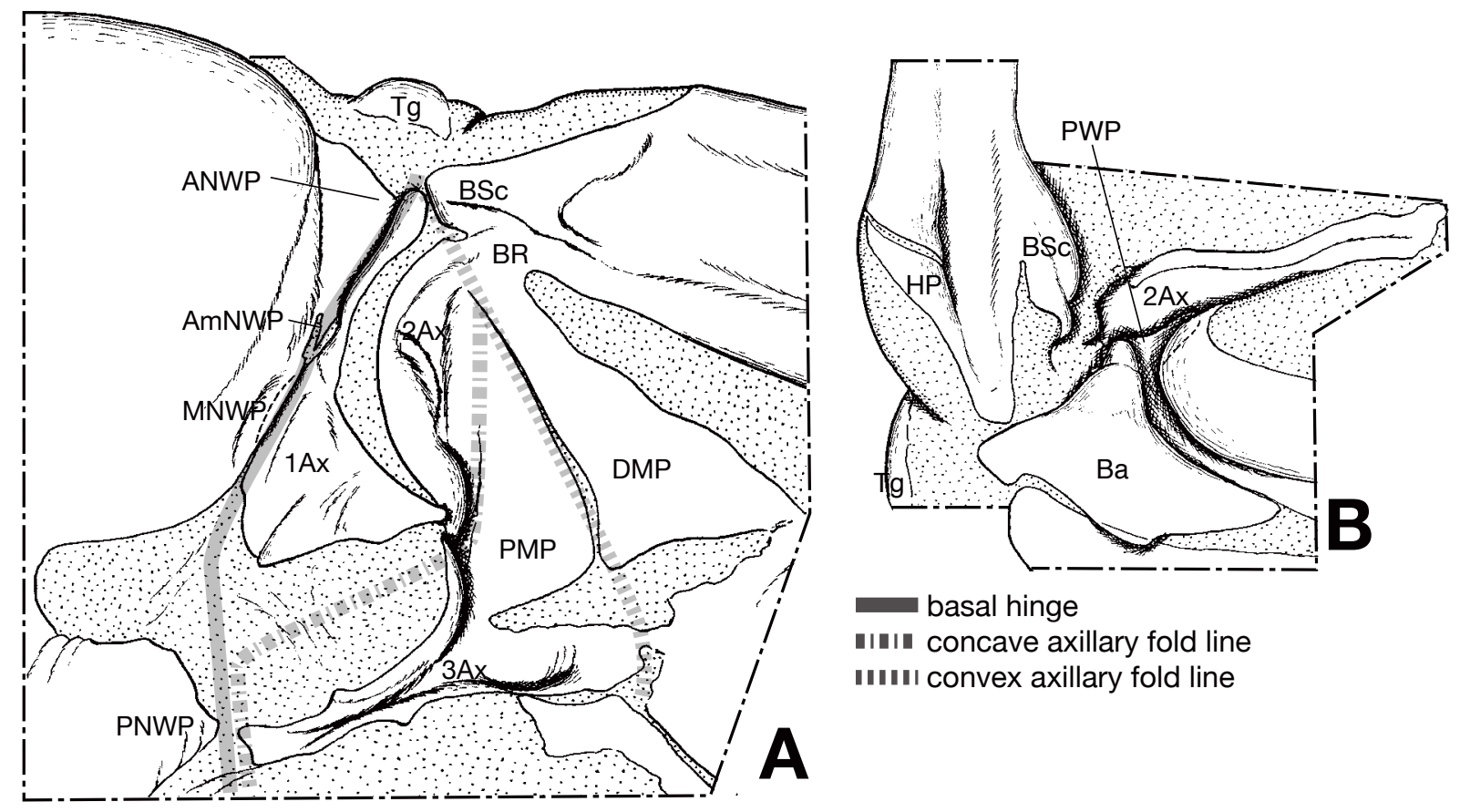



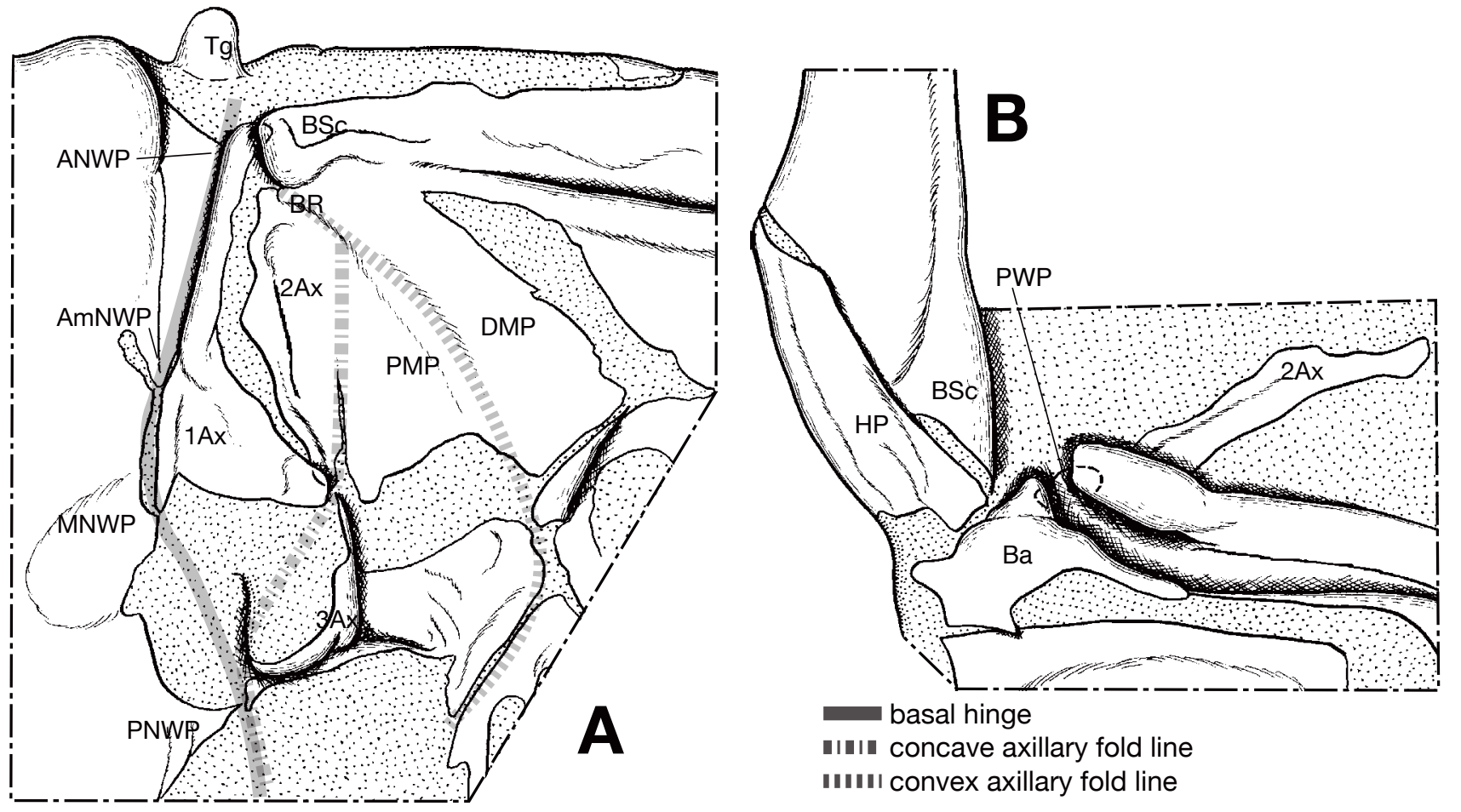

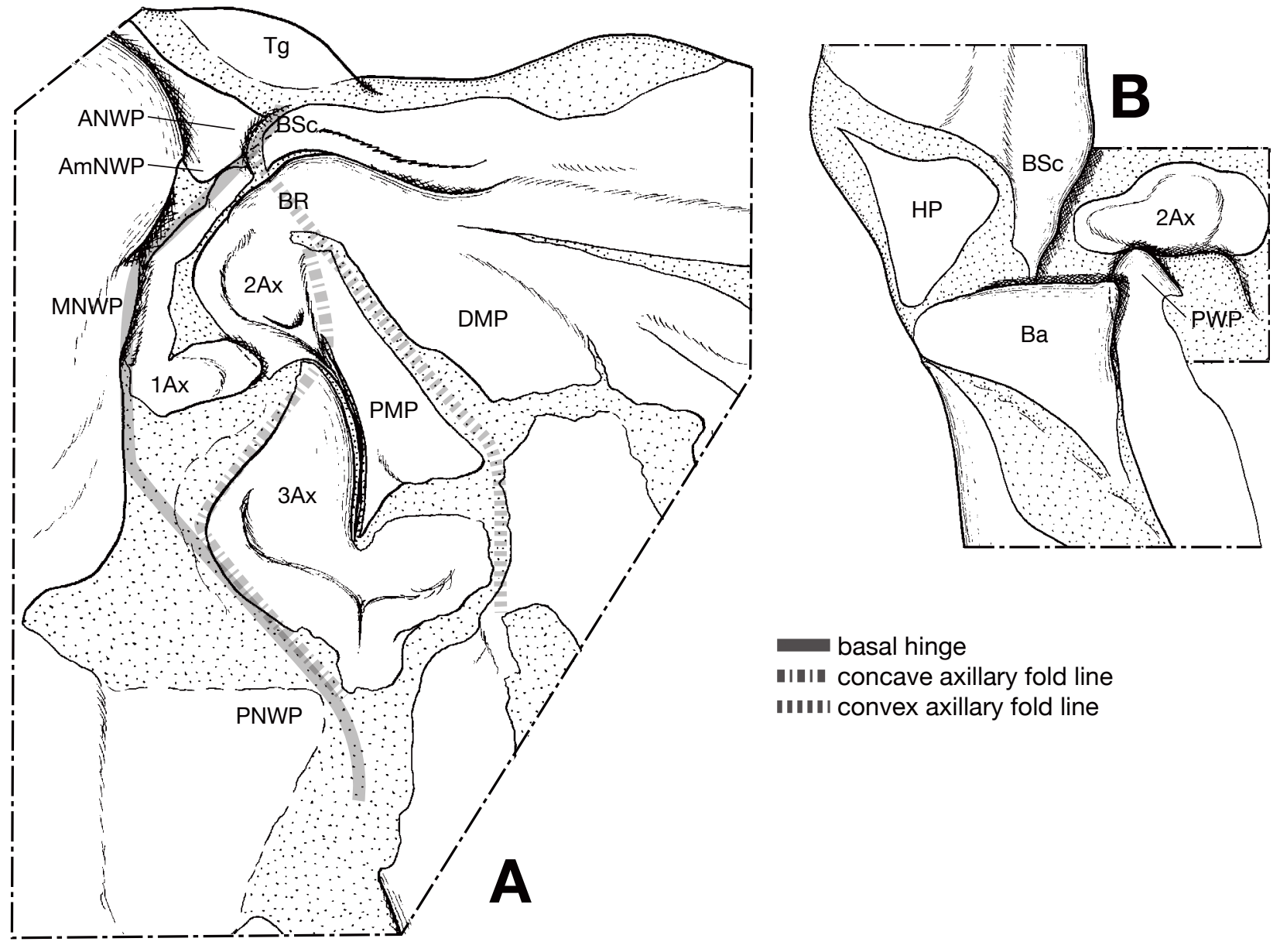

basal hinge

1. concave axillary fold line

Iu u convex axillary fold line 

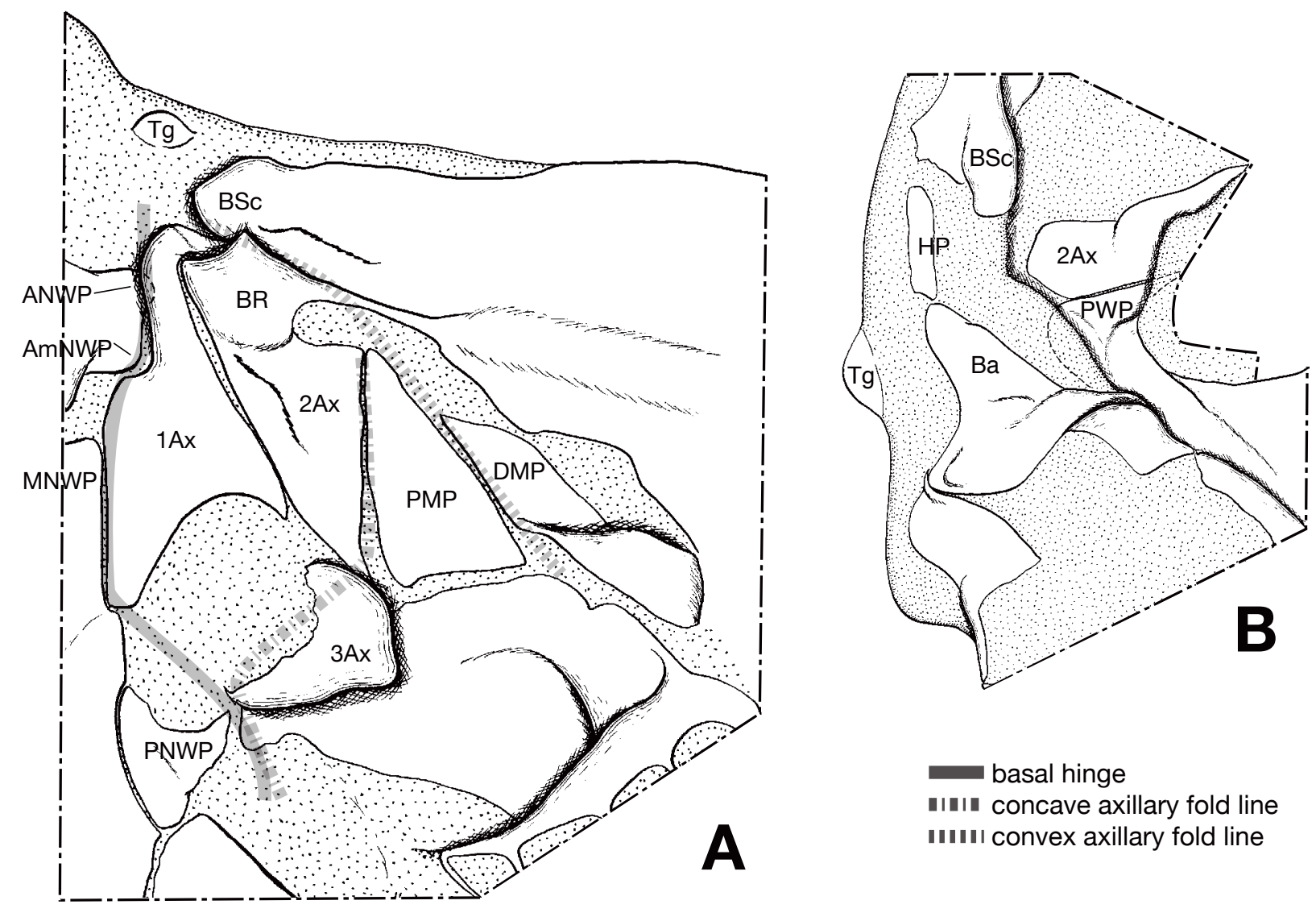

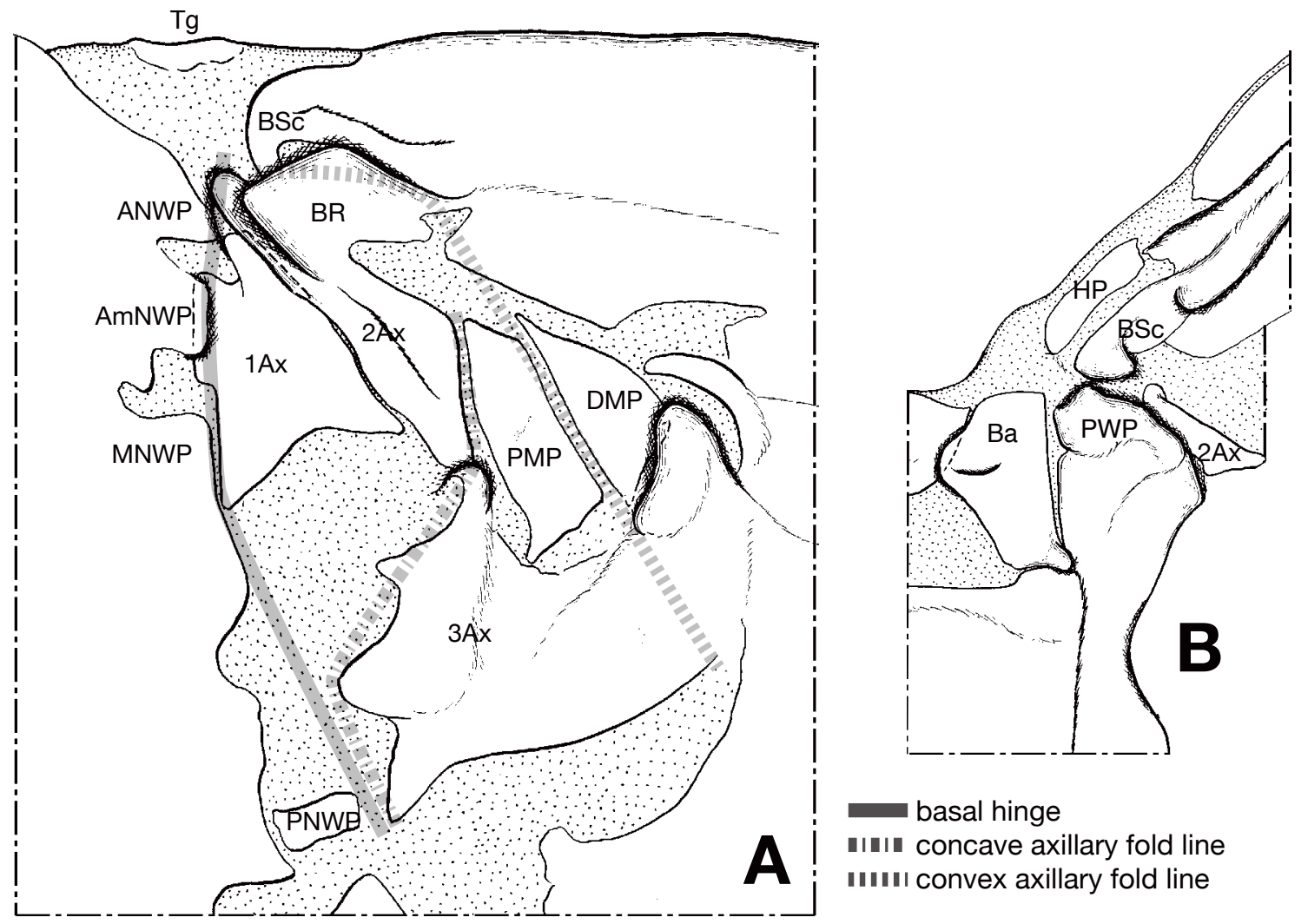

basal hinge

III concave axillary fold line Iu u convex axillary fold line 

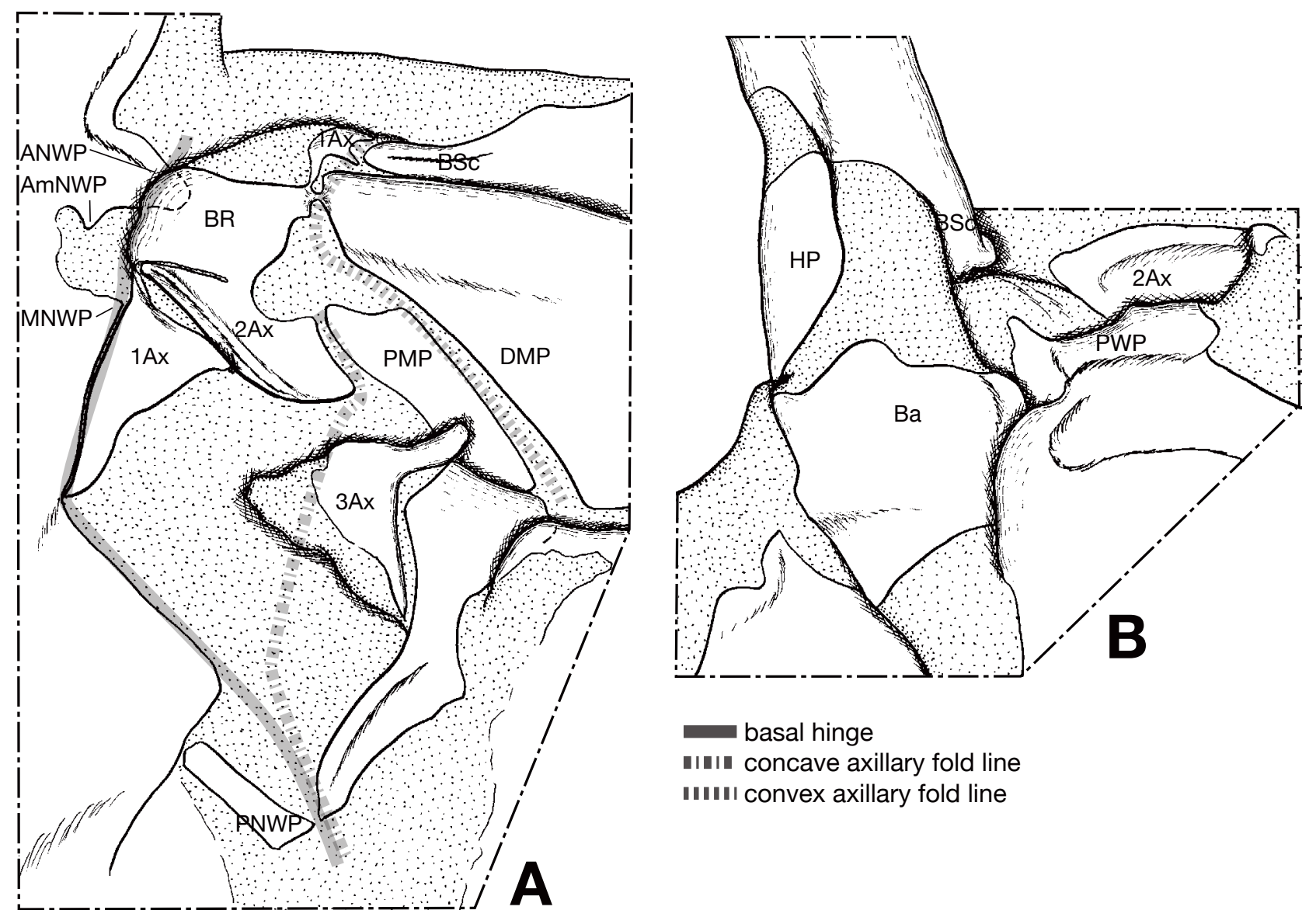

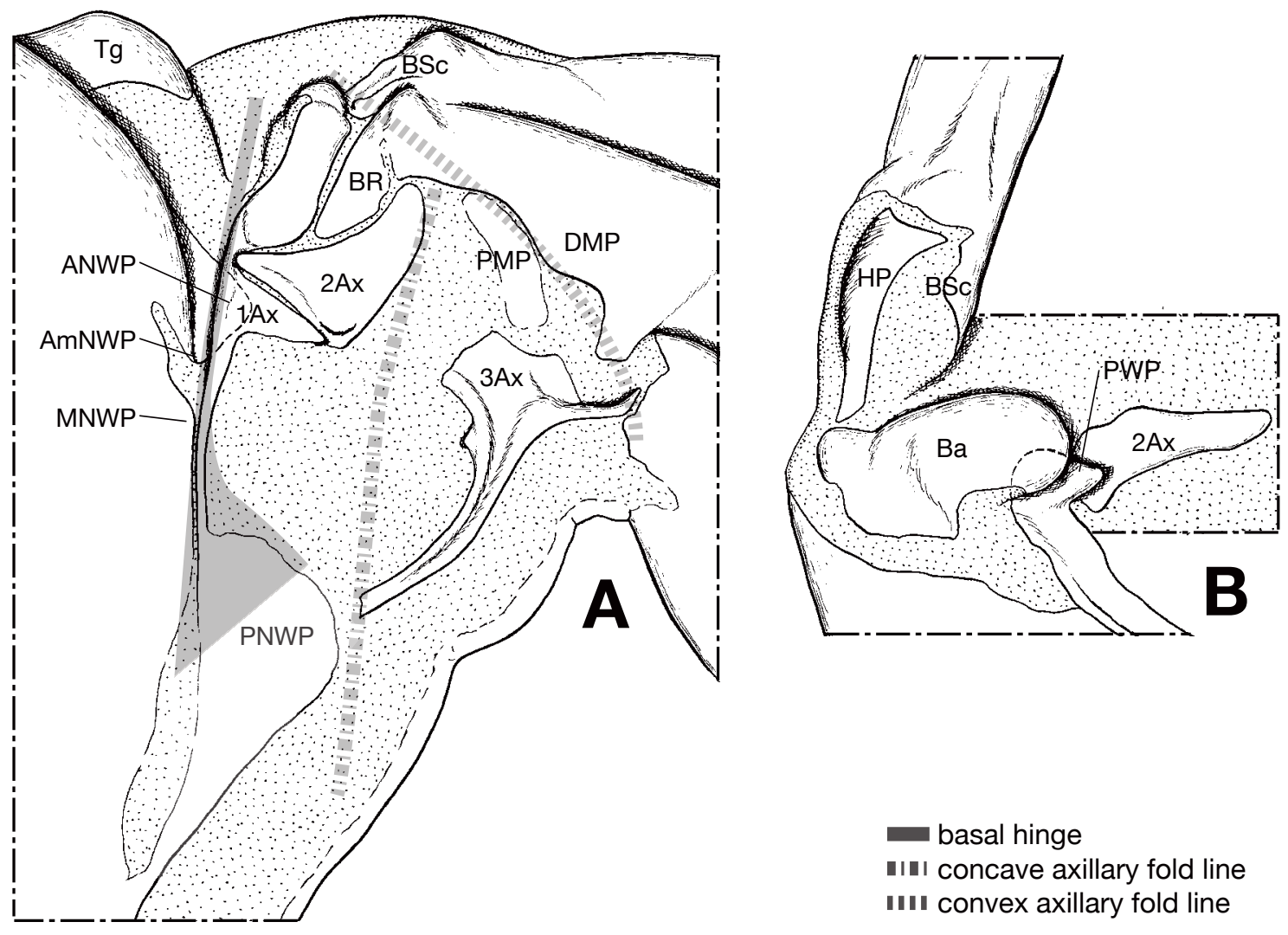

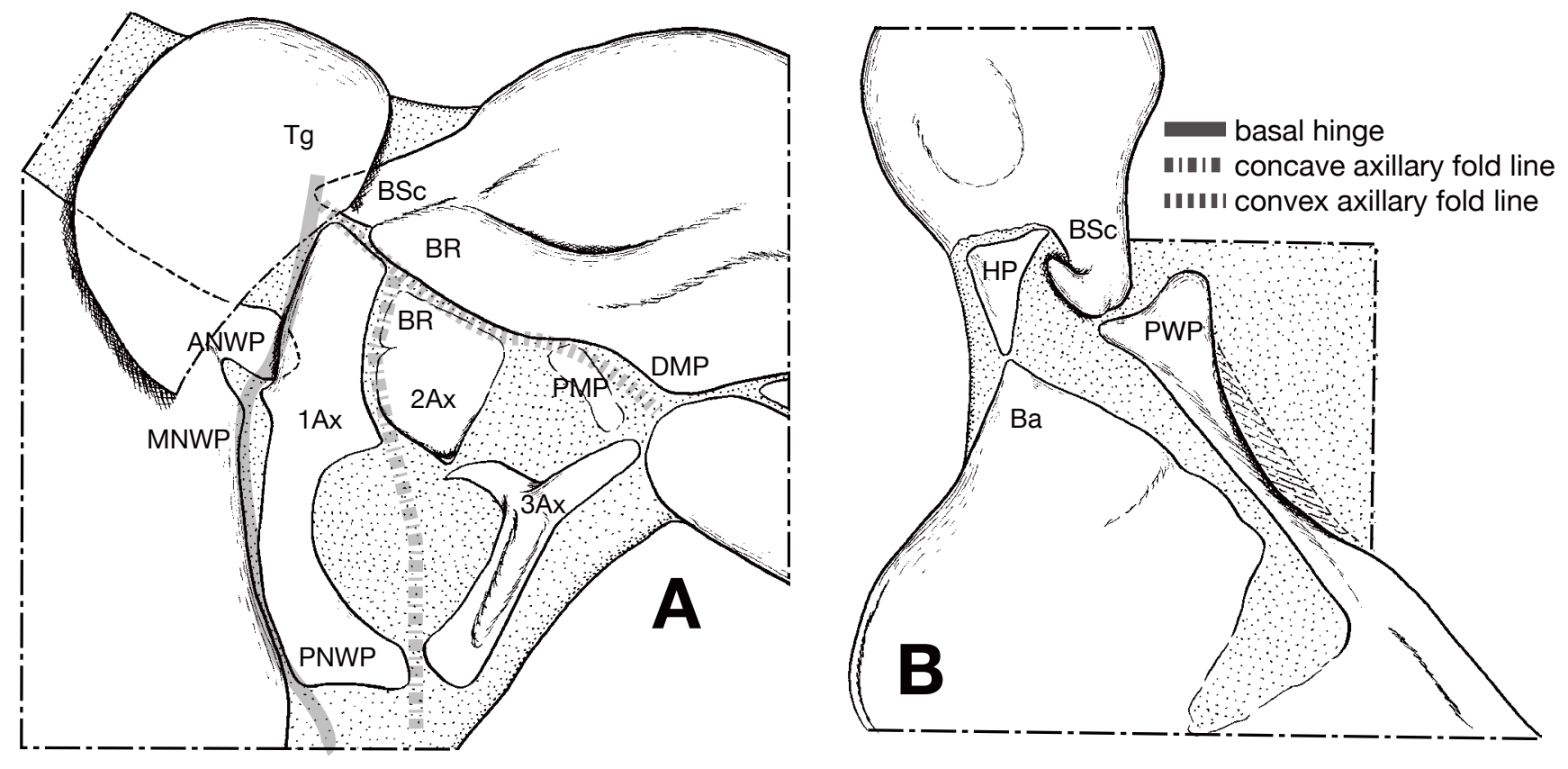

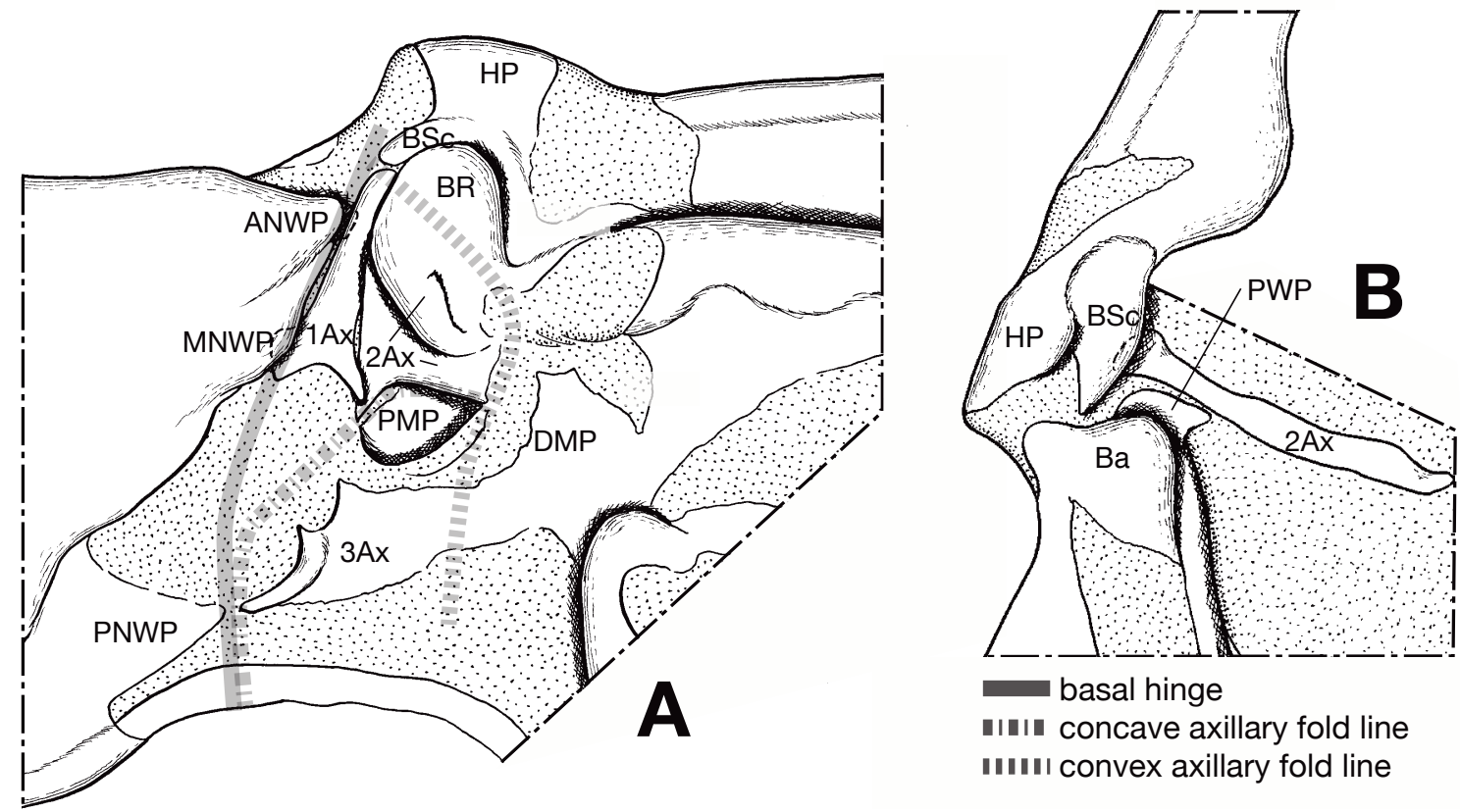

Fig. 

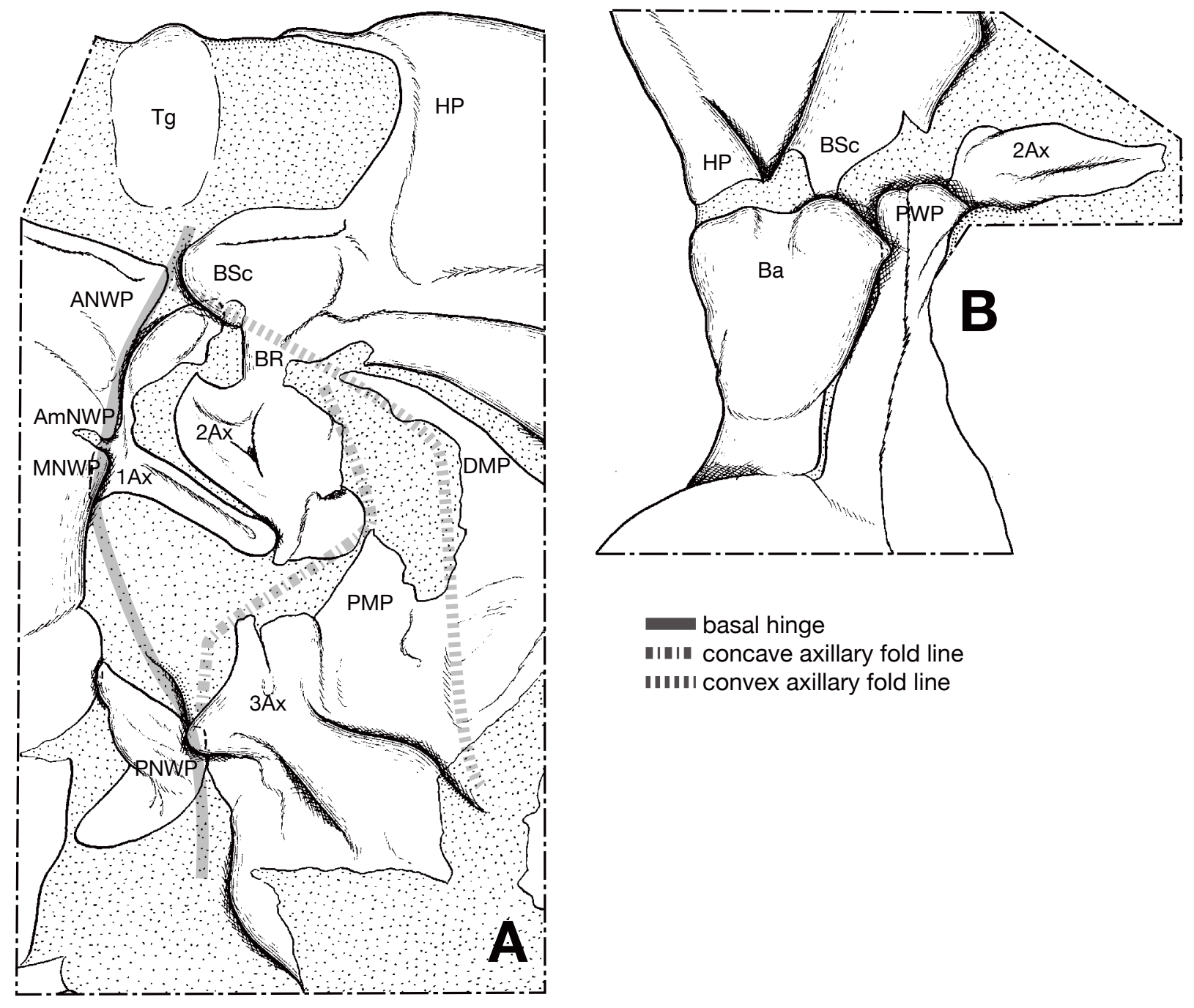

basal hinge

-I. concave axillary fold line

uuu convex axillary fold line 


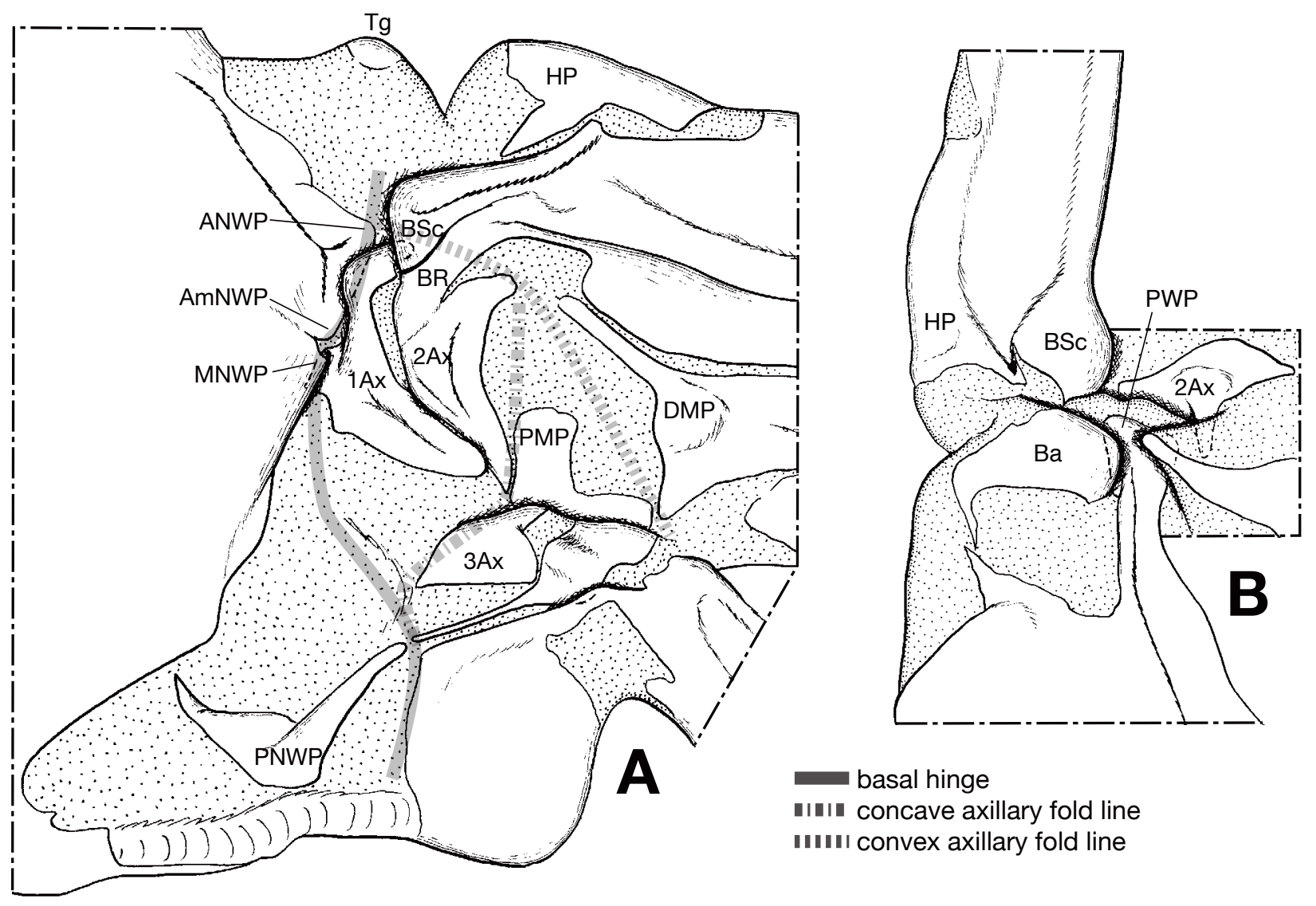




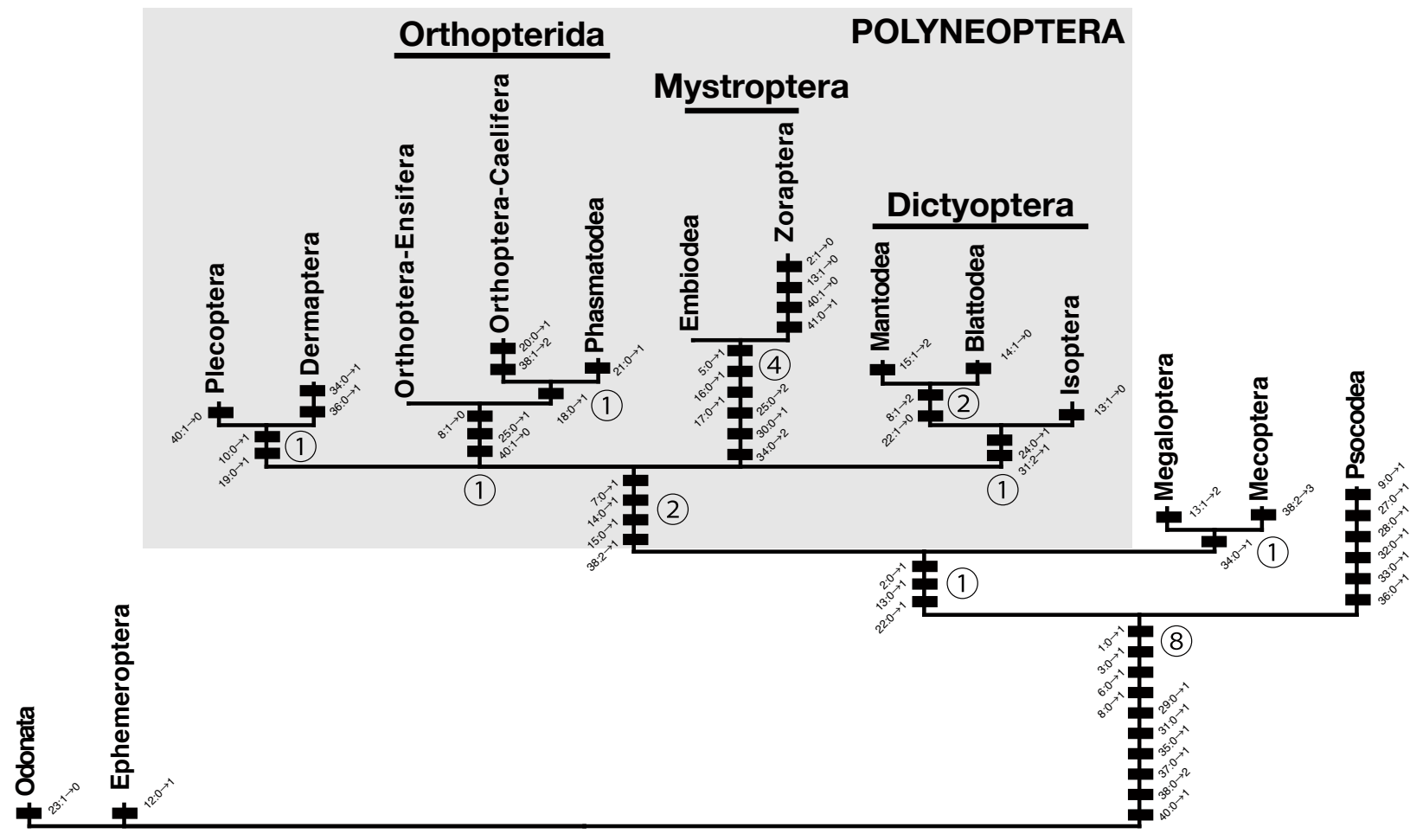




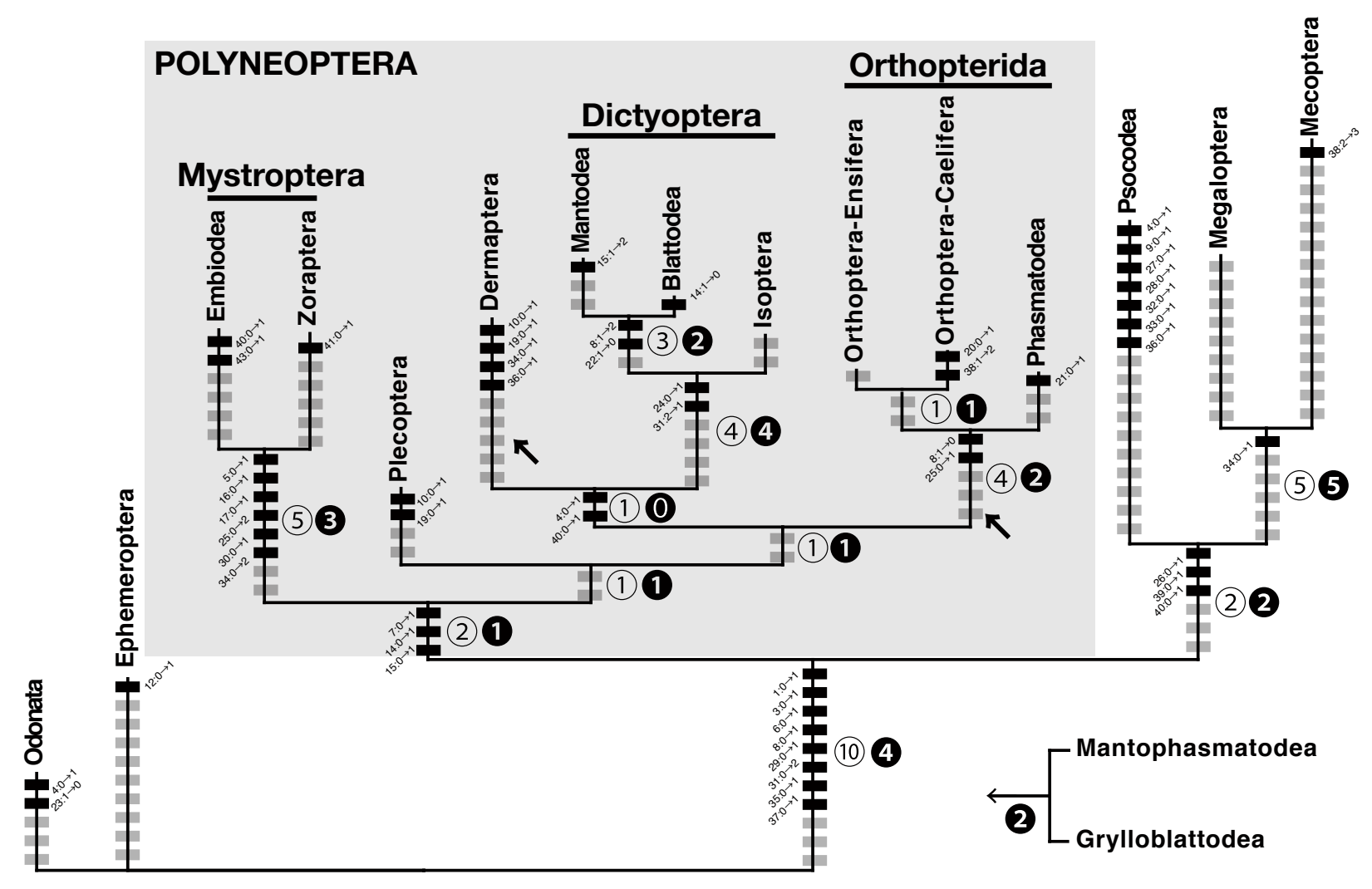

